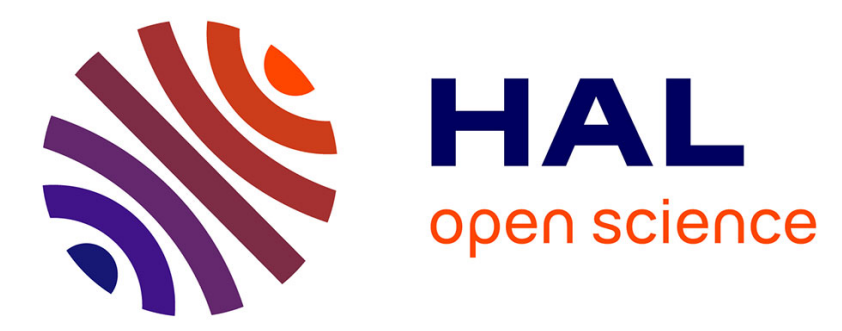

\title{
Modeling the shortening history of a fault tip fold using structural and geomorphic records of deformation
}

\author{
Mathieu Daëron, Jean-Philippe Avouac, Julien Charreau
}

\section{To cite this version:}

Mathieu Daëron, Jean-Philippe Avouac, Julien Charreau. Modeling the shortening history of a fault tip fold using structural and geomorphic records of deformation. Journal of Geophysical Research: Solid Earth, 2007, 112 (B3), pp.3-13. 10.1029/2006JB004460 . hal-02904266

\section{HAL Id: hal-02904266 https://hal.science/hal-02904266}

Submitted on 27 Jul 2020

HAL is a multi-disciplinary open access archive for the deposit and dissemination of scientific research documents, whether they are published or not. The documents may come from teaching and research institutions in France or abroad, or from public or private research centers.
L'archive ouverte pluridisciplinaire HAL, est destinée au dépôt et à la diffusion de documents scientifiques de niveau recherche, publiés ou non, émanant des établissements d'enseignement et de recherche français ou étrangers, des laboratoires publics ou privés. 


\title{
Modeling the shortening history of a fault tip fold using structural and geomorphic records of deformation
}

\author{
Mathieu Daëron, ${ }^{1}$ Jean-Philippe Avouac, ${ }^{1}$ and Julien Charreau ${ }^{2}$ \\ Received 21 April 2006; revised 4 October 2006; accepted 30 October 2006; published 10 March 2007.
}

[1] We present a methodology to derive the growth history of a fault tip fold above a basal detachment. Our approach is based on modeling the stratigraphic and geomorphic records of deformation, as well as the finite structure of the fold constrained from seismic profiles. We parameterize the spatial deformation pattern using a simple formulation of the displacement field derived from sandbox experiments. Assuming a stationary spatial pattern of deformation, we simulate the gradual warping and uplift of stratigraphic and geomorphic markers, which provides an estimate of the cumulative amounts of shortening they have recorded. This approach allows modeling of isolated terraces or growth strata. We apply this method to the study of two fault tip folds in the Tien Shan, the Yakeng and Anjihai anticlines, documenting their deformation history over the past 6-7 Myr. We show that the modern shortening rates can be estimated from the width of the fold topography provided that the sedimentation rate is known, yielding respective rates of 2.15 and $1.12 \mathrm{~mm} / \mathrm{yr}$ across Yakeng and Anjihai, consistent with the deformation recorded by fluvial and alluvial terraces. This study demonstrates that the shortening rates across both folds accelerated significantly since the onset of folding. It also illustrates the usefulness of a simple geometric folding model and highlights the importance of considering local interactions between tectonic deformation, sedimentation, and erosion.

Citation: Daëron, M., J.-P. Avouac, and J. Charreau (2007), Modeling the shortening history of a fault tip fold using structural and geomorphic records of deformation, J. Geophys. Res., 112, B03S13, doi:10.1029/2006JB004460.

\section{Introduction}

[2] In regions of active folding and thrusting, cumulative deformation of geomorphic surfaces such as alluvial or fluvial terraces (Figure 1) can be used to constrain modern rates of horizontal shortening [Rockwell et al., 1988; Lavé and Avouac, 2000; Benedetti et al., 2000; Thompson et al., 2002]. At deeper levels, pretectonic geologic units record finite shortening across the fold, while intermediate growth strata, deposited as the fold was already growing and sometimes exposed at the surface (Figure 1), document the long-term shortening history [Suppe et al., 1992; Epard and Groshong, 1993; Hardy and Poblet, 1994; Storti and Poblet, 1997; Gonzalez-Mieres and Suppe, 2006]. It should therefore be possible to retrieve the complete history of fold growth from the joint interpretation of the geomorphic record of recent deformation and the subsurface structure of a fold.

[3] Linking surface uplift to horizontal shortening can be challenging, however. Where a marker is preserved continuously across a fold, conservation of cross-sectional area allows estimating the cumulative horizontal shortening

\footnotetext{
${ }^{1}$ Division of Geological and Planetary Sciences, California Institute of Technology, Pasadena, California, USA.

${ }^{2}$ Institut des Sciences de la Terre d'Orléans, Orléans, France.

Copyright 2007 by the American Geophysical Union. 0148-0227/07/2006JB004460\$09.00
}

experienced by that marker, provided that the deep geometry of the underlying fault is known [Lavé and Avouac, 2000]. In many cases, however, geomorphic markers are not continuously observable, either due to erosion or to partial burying under younger sediments (Figure 1). In that case, the area conservation method is not applicable. An alternative approach then consists in relying on some explicit function relating uplift to horizontal shortening. For example, in fault bend folds, where bedding-parallel motion is expected, horizontal shortening can be equated to uplift divided by the sine of structural dip [Lavé and Avouac, 2000].

[4] Such a formulation, however, is not always available for other types of fold, in particular for fault tip folds, where rocks are deformed in a broad zone above the termination (or "tip") of a thrust or detachment fault [Dahlstrom, 1990; Suppe and Medwedeff, 1990; Mitra, 2003]. The sketch in Figure 1 shows such a fold, where horizontal shortening above the tip of a basal detachment is compensated by layer thickening, which manifests as warping and uplift of the surface. This pattern of deformation is observed in relatively young folds, because strain tends to localize after a certain amount of distributed shortening, and the system evolves toward more mature structures such as fault propagation or fault bend folds [Suppe, 1983; Mitra, 2003; Avouac et al., 1993]. Although the situation depicted in Figure 1 is similar to trishear fault propagation folding [Almendinger, 1998], where deformation at the front of a fault tip is modeled by 


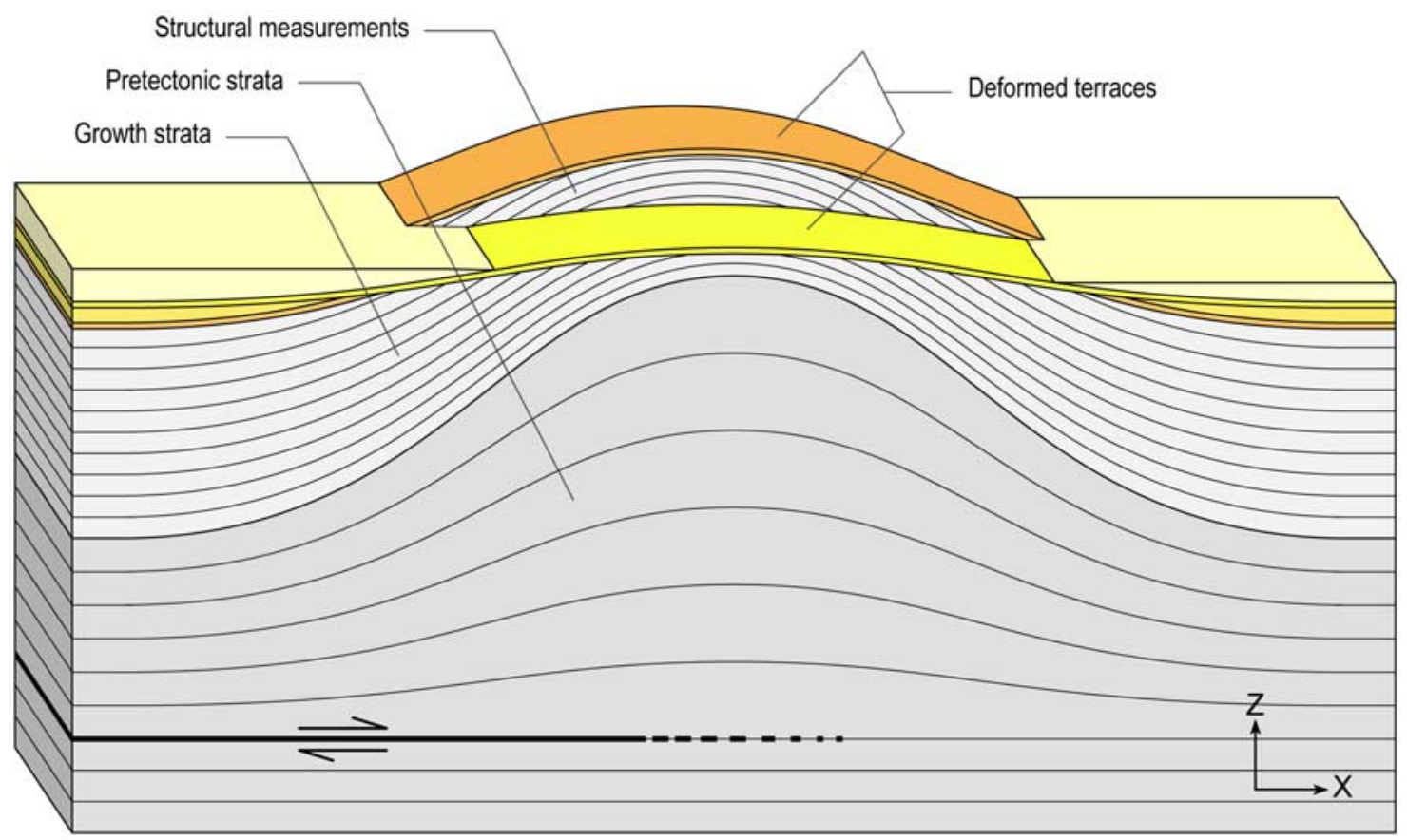

Figure 1. Synthetic sketch of the structural and geomorphic record of deformation, in the case of fold formed above the tip (dashed thick line) of a detachment fault.

distributed shear in a triangle, the trishear formulation does not apply directly in the case of a propagating detachment since it requires that the triangle contains the extrapolated fault plane, which is not the case in Figure 1.

[5] Analog experiments by Bernard et al. [2007] support a simple analytical formulation of the displacement field produced by incremental shortening of such a system (Appendix A), and this formulation has been used to analyze the growth of Pakuashan anticline along the western foothills of Taiwan [Simoes et al., 2007b]. In order to further explore this methodology, we use the same formulation to model the growth of two case examples of young fault tip folds located in the fold-and-thrust belts that bound the Tien Shan range, in Central Asia, for which good seismic data are available [He et al., 2005; Hubert-Ferrari et al., 2005, 2007; Gonzalez-Mieres and Suppe, 2006]. The displacement model's parameters, which govern the finite shape of the fold, are estimated based on seismic imaging of deep pregrowth strata. The same seismic data are also used to constrain the finite amount of shortening and the stratigraphic depth of fold initiation. Assuming that the deformation pattern has not varied significantly over the fold's history, which is a reasonable hypothesis for our case examples, we use the parameterized displacement model to deform incrementally a cross section of the fold, progressively adding syntectonic markers, so as to reproduce surface data such as present-day relief, the shape of alluvial and fluvial terraces, and field-measured structural dip angles. Comparing the predicted and observed finite geometries allows to test the validity of our assumptions regarding the initial geometry of markers, and to estimate the amount of shortening recorded by each of them. We emphasize that the objective of the present study is not to characterize in detail the history of two specific folds, but rather to lay out the requirements and potential benefits of our modeling approach.

\section{Regional Setting}

[6] The Tien Shan range, in Central Asia, is one of the highest and most rapidly deforming intracontinental mountain belts on Earth (Figure 2). It stretches along $2500 \mathrm{~km}$ between the Tarim and Junggar basins, with peaks generally higher than $4500 \mathrm{~m}$ above sea level. Following a complex, subduction-related Paleozoic history [Burtman, 1975; Windley et al., 1990], it was reactivated in the early to middle Miocene [Hendrix et al., 1994; Métivier and Gaudemer, 1997; Sobel and Dumitru, 1997; Bullen et al., 2001; Dumitru et al., 2001; Charreau et al., 2005, 2006] as a long-term and long-range consequence of the indentation of India into Asia, and accommodated up to $200 \mathrm{~km}$ of cumulative Cenozoic shortening [Tapponnier and Molnar, 1977; Avouac et al., 1993].

[7] High levels of seismicity, GPS measurements and spectacular evidence of surface faulting and folding all attest to ongoing, rapid deformation. At the longitude of our study $\left(83-86^{\circ} \mathrm{E}\right)$, the $6 \mathrm{~mm} / \mathrm{yr}$ GPS shortening rate across the Tien Shan [Reigber et al., 2001] is taken up by active faulting within the range and by two fold-and-thrust belts that mark its northern and southern boundaries (Figure 2). In these piedmonts, overthrusting of the Tarim and Junggar basins manifests as E-W alignments of active anticlines which deform alluvial and fluvial terraces. The frontmost folds (basinward) are the youngest. They generally form above blind detachments in the early Jurassic and/ or Tertiary sediments of the foreland (in coal- and gypsumrich strata, respectively), and take up a significant part of the 


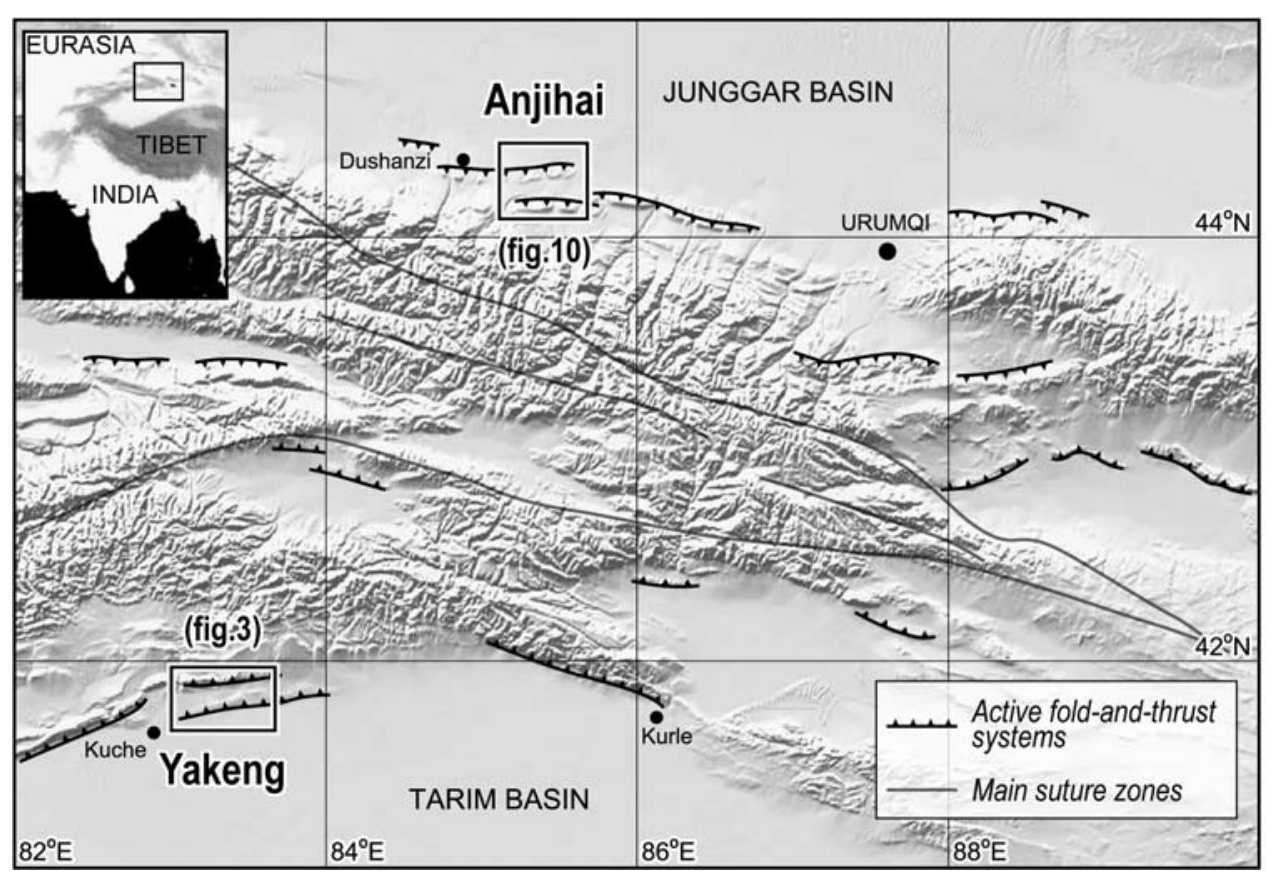

Figure 2. Simplified map of the eastern Tien Shan area. Black boxes mark locations of the folds modeled in this study. Black barbed lines show locations of identified zones of active thrusting and folding. Gray lines show approximate traces of the north Tien Shan and south Tien Shan suture zones.

active shortening [Avouac et al., 1993; Molnar et al., 1994; Burchfiel et al., 1999].

[8] We selected two of these frontmost piedmont folds as modeling targets (Figure 2), seeking to take full advantage of the rapid deformation rates and of the wealth of available data (seismic reflection profiles, structural exposure by river incision, well-preserved alluvial and fluvial terraces, magnetostratigraphic time constraints). The first of these folds is the Yakeng anticline, a well-imaged fault tip fold above a blind basal detachment, which has been the focus of previous investigations [Poisson, 2002; Hubert-Ferrari et al., 2005, 2007; Gonzalez-Mieres and Suppe, 2006]. Our intent here is to make use of the tight existing structural constraints to model the geomorphic record of deformation. The Anjihai anticline is another example of a similar fold. Its geomorphic expression is comparable but not identical to that of Yakeng. Although the structure at depth of Anjihai is less tightly constrained, it constitutes a good target for our modeling approach because reliable seismic or geomorphic markers cannot be traced continuously across the fold, although there is abundant local evidence for growth strata and folded alluvial surfaces.

\section{Chronological Constraints on Stratigraphy}

[9] Our geometric modeling does not directly provide timing information. It does, however, constrain cumulative shortening as a function of stratigraphic depth, which can then be converted to ages using the recent magnetostratigraphic studies of Charreau et al. [2005, 2006] and Charreau [2005]. These studies show evidence for remarkably constant sedimentation rates over the past $10.5 \mathrm{Myr}$ (Figure 3). In the Yaha section (southern piedmont, location in Figure 4), less than $20 \mathrm{~km}$ upstream from the Yakeng fold, Charreau et al. [2006] measured an nearly uniform sedimentation rate of $\sim 0.43 \mathrm{~mm} / \mathrm{yr}$ between 11 and $5.2 \mathrm{Ma}$. In the Kuitun He section (northern piedmont), they found evidence for a similarly constant rate of $\sim 0.21 \mathrm{~mm} / \mathrm{yr}$ from 10.5 to $3.1 \mathrm{Ma}$ [Charreau et al., 2005], and for a 10.5 to $8.5 \mathrm{Ma}$ rate of $\sim 0.27 \mathrm{~mm} / \mathrm{yr}$ in the Jingou He section [Charreau, 2005], $40 \mathrm{~km}$ east of the previous and less than $20 \mathrm{~km}$ upstream from Anjihai (location in Figure 12 in section 5.1). Between the modern surface and the stratigraphic level of the top of each section, constrained by seismic profiles [He et al., 2005], average sedimentation rates are very similar to the respective magnetostratigraphic rates since 10-11 Ma (Figure 3). Although Zhang et al. [2001] argued for a tenfold increase in sedimentation rates around 5 Ma near Manas, along the northern margin of the Tien Shan, there is no evidence for such an acceleration in the Kuitun $\mathrm{He}$ data, $100 \mathrm{~km}$ to the west along the same piedmont (Figure 3). Although this might be attributed to strong lateral variations (from a tenfold acceleration to a negligible one over $100 \mathrm{~km}$ ), the average sedimentation rate over the past 8.5 Myr at the Jingou He site, between the top of the nonfolded section and the modern surface, is also indistinguishable from the constant $0.27 \mathrm{~mm} / \mathrm{yr}$ regime between 10.5 and $8.5 \mathrm{Ma}$, which is difficult to reconcile with a major acceleration since 8.5 Ma [Charreau, 2005]. At larger scales, Métivier and Gaudemer [1997] reconstructed the mass accumulation history of the Tarim and Junggar basins, finding evidence for a significant increase between the average late Miocene and Pliocene sedimentation rates. However, as pointed out by Métivier and Gaudemer [1997] and Métivier et al. [1999], rates estimated form a single section might not be representative of the evolution of the total flux of sediments, allowing for variations in local sedimentation histories at different sites. 

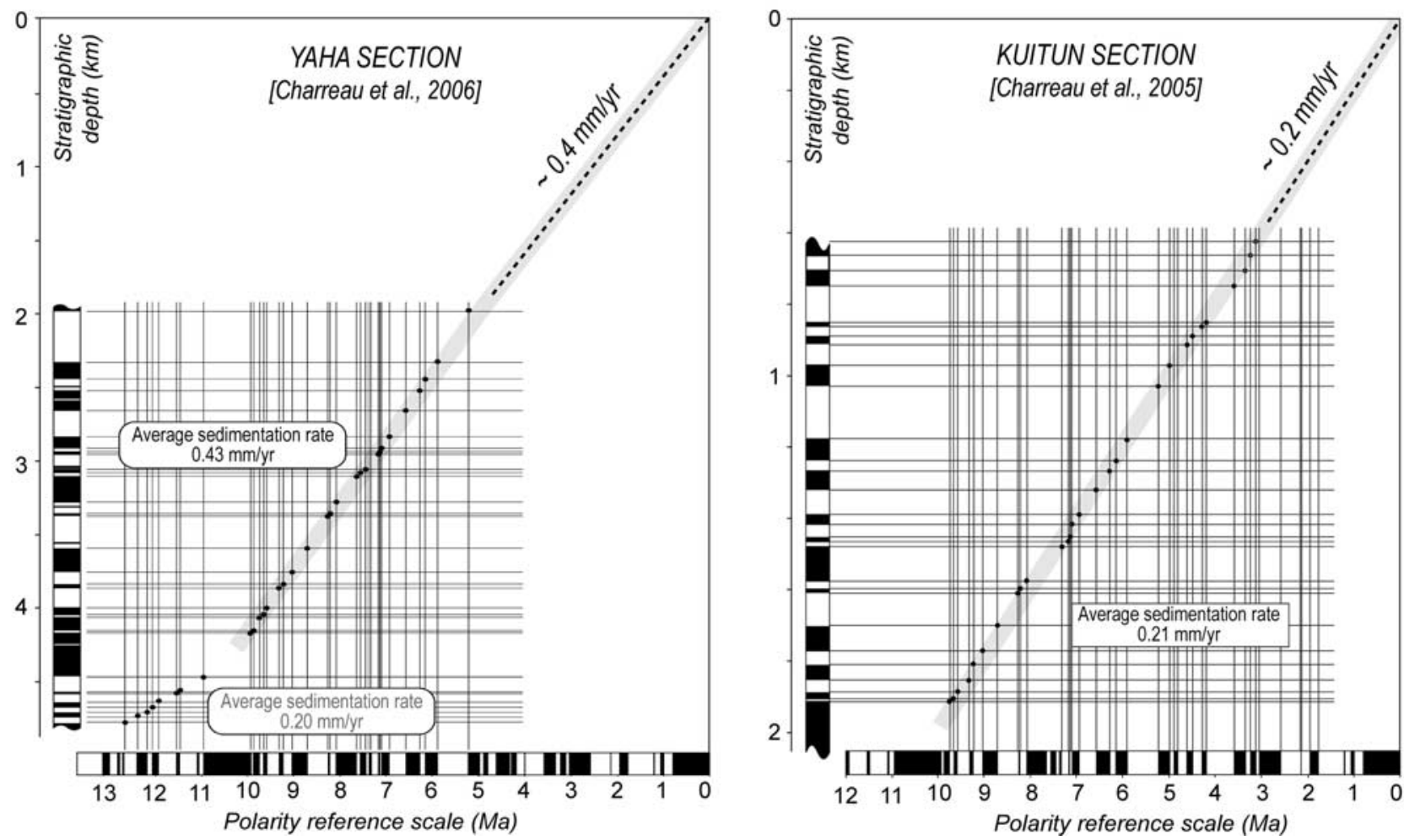

Figure 3. Magnetostratigraphic plots of depth versus age for the Yaha and Kuitun He sections (plots modified from Charreau et al. [2006] and Charreau et al. [2005], respectively). Each plot is based on paleomagnetic measurements from more than 800 samples. The resulting sedimentation rates appear remarkably constant since $\sim 10.5 \mathrm{Ma}$ and are very similar to the average rates between the surface and the top of each section (dashed extrapolation lines).

Overall, the available local magnetostratigraphic data imply that, at the two sites discussed in this study, old sedimentation rates $(10.5-5.2 \mathrm{Ma}$ at Yaha and $10.5-8.5 \mathrm{Ma}$ at Jingou He) may be extrapolated over millions of years, possibly up to late Pleistocene times, consistent with recent rates of $\sim 0.43 \mathrm{~mm} / \mathrm{yr}$ near Yakeng and $\sim 0.27 \mathrm{~mm} / \mathrm{yr}$ near Anjihai.

\section{Yakeng}

\subsection{Description}

[10] The Yakeng anticline stretches for $\sim 100 \mathrm{~km}$ east of the town of Kuqa, along the southern Tien Shan piedmont (Figures 2 and 4). At the surface, it manifests as a gentle, 5- to 10 -km-wide, $\sim 150$-m-high ridge resulting from the folding of a large-scale, south dipping alluvial terrace, noted $\mathrm{Ta}$, whose age is loosely constrained to be older than $\sim 34$ ka from optically stimulated luminescence (OSL) dating [Poisson, 2002]. Ta is generally well preserved (Figure 5), although south flowing rivers dissect it in a number of locations, forming steep, narrow gorges. The Yakeng cross section discussed below corresponds to the ridge-perpendicular seismic profile reported on the map in Figure 4 and shown in Figure 6. About $10 \mathrm{~km}$ to the east of the profile, Ta is incised by the East Quilitag river, which formed and abandoned a partially preserved fluvial terrace (Tf). Since then, ongoing deformation has folded and uplifted Tf, bringing it about $25 \mathrm{~m}$ above the modern river [Poisson, 2002]. Although the age of Tf is unknown, Poisson [2002] inferred it to be similar to that of another fluvial terrace near Kuqa, OSL dated to $10.6 \pm 1 \mathrm{ka}$.

[11] The continuous morphology along the axis of the fold and the lack of evidence for along-strike shear suggest that displacements perpendicular to a SSE trending cross section are negligible, allowing for local approximation of the Yakeng anticline as a two-dimensional (2-D) cylindrical structure. This geomorphic continuity, while it does not preclude along-strike variations of the cross-sectional structure, suggests that such changes would manifest on the scale of at least a few kilometers. Seismic imaging (Figure 6) reveals that the width of the structural fold is more than twice that of the emergent Ta, because the latter is buried under sediments on the outer flanks of the anticline. At depth the amplitude of folding generally decreases downward, consistent with the geometry of a fault tip fold growing above a 6-km-deep basal detachment coinciding with reflector L4, in the evaporites of the Oligo-Miocene Jidikeh formation [Hubert-Ferrari et al., 2005]. Because of a complex basement geometry below the anticline, and due to the proximity of the Yanan fold, it is not straightforward to use traditional relief area methods to analyze shortening across Yakeng. The complexities of the deeper Yakeng structure are beyond the scope of this study, and are discussed in some detail by Hubert-Ferrari et al. [2005] and Gonzalez-Mieres and Suppe [2006]. The latter, using measurements of thickness relief area, estimated the mean 


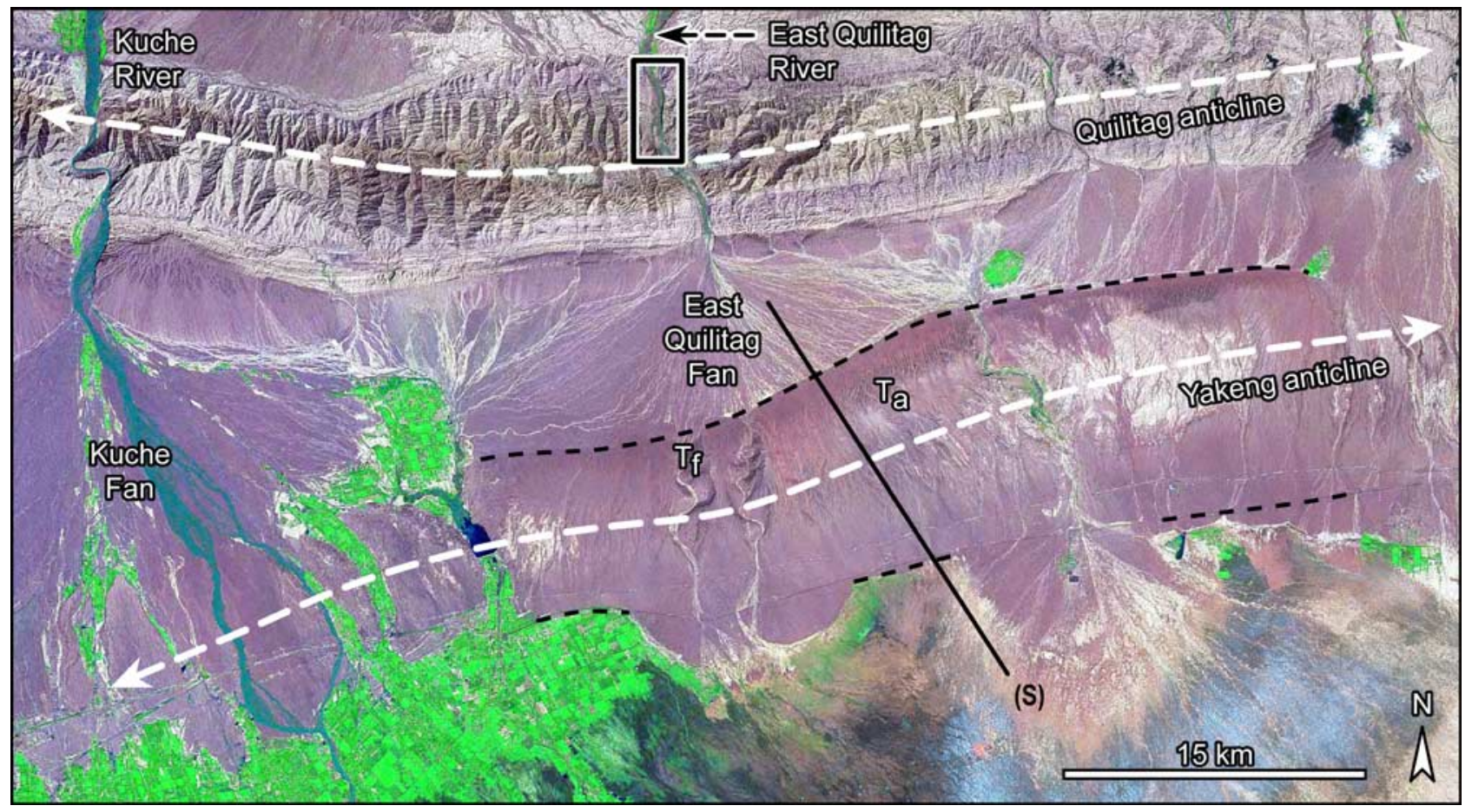

Figure 4. Map of Yakeng area. Dashed white lines represent anticlinal axes of Yakeng and Quilitag folds. Solid black line (S) marks location of seismic profile [He et al., 2005]. Dashed black line follows the outline of alluvial terrace Ta. "Tf " label shows location of preserved sections of fluvial terrace Tf (not mapped at this scale). Black box along East Quilitag river marks location of the magnetostratigraphic section of Charreau et al. [2006].

finite shortening to be $1.2 \mathrm{~km}$, and showed that folded reflectors L5 to L14 are pretectonic.

\subsection{Parameters of the Deformation Model}

[12] While the geometric complexity of the deep part of the fold justifies studying it in the thickness domain [Gonzalez-Mieres and Suppe, 2006], our incremental deformation approach requires an explicit definition of the initial undeformed geometry of each marker. Considering that the analysis of Gonzalez-Mieres and Suppe [2006] is reliable, we assume a priori that L14 is the youngest pretectonic reflector, while L15 and above are syntectonic. In order to parameterize our displacement field model, we only consider the syntectonic units, because the irregular shape of pretectonic markers obscure the pattern of deformation below L15.

[13] To define the initial, undeformed geometry of seismic reflectors L15 to L27, we consider two zones which we assume to be unaffected by the Yakeng anticline (gray boxes in Figure 7). The slopes of markers upstream from the fold are systematically steeper than downstream of it ( $\sim 3 \%$ versus $1 \%$ ), which precludes approximating the initial geometries as straight lines. Fitting independently each reflector using a higher-order polynomial would yield geometries with different curvatures from one reflector to another, generating unrealistic thickness changes and obscuring the variation of relief area as a function of depth. To address these issues, we call upon a two-stage approach. First we fit each undeformed marker, independently from one other, using a straight line (Figure 7a). The 13 independent linear fits, noted LF15 to LF27, have different

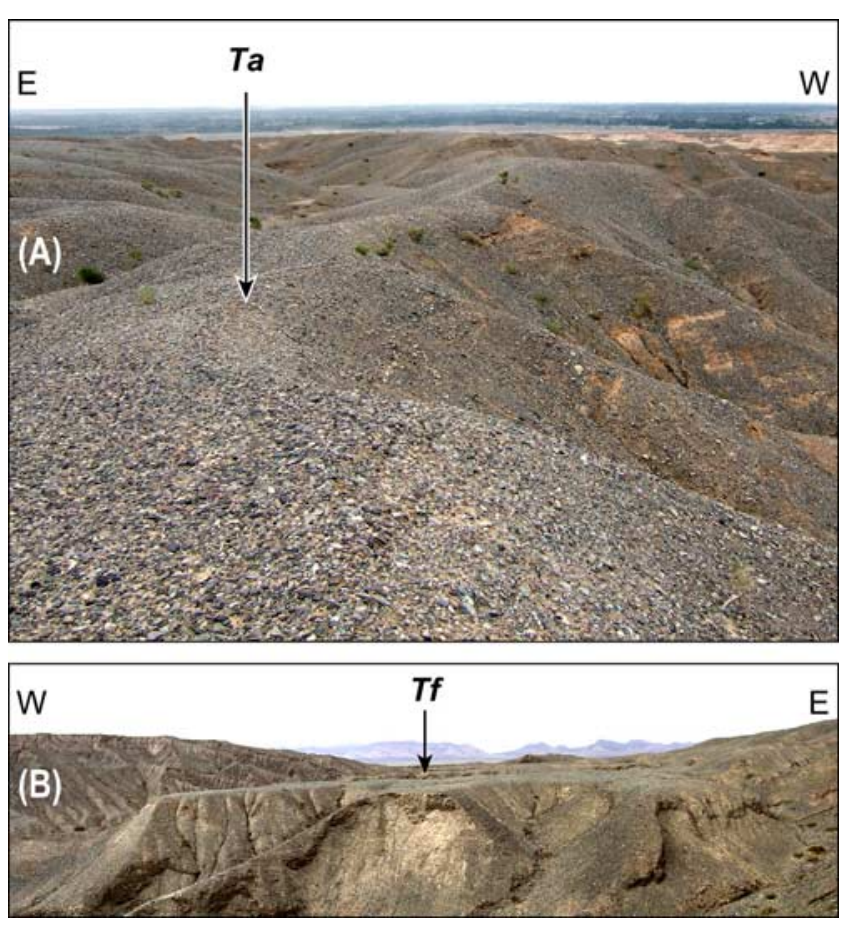

Figure 5. Field photographs of Yakeng surface fold: (a) alluvial terrace Ta and (b) fluvial terrace Tf. 

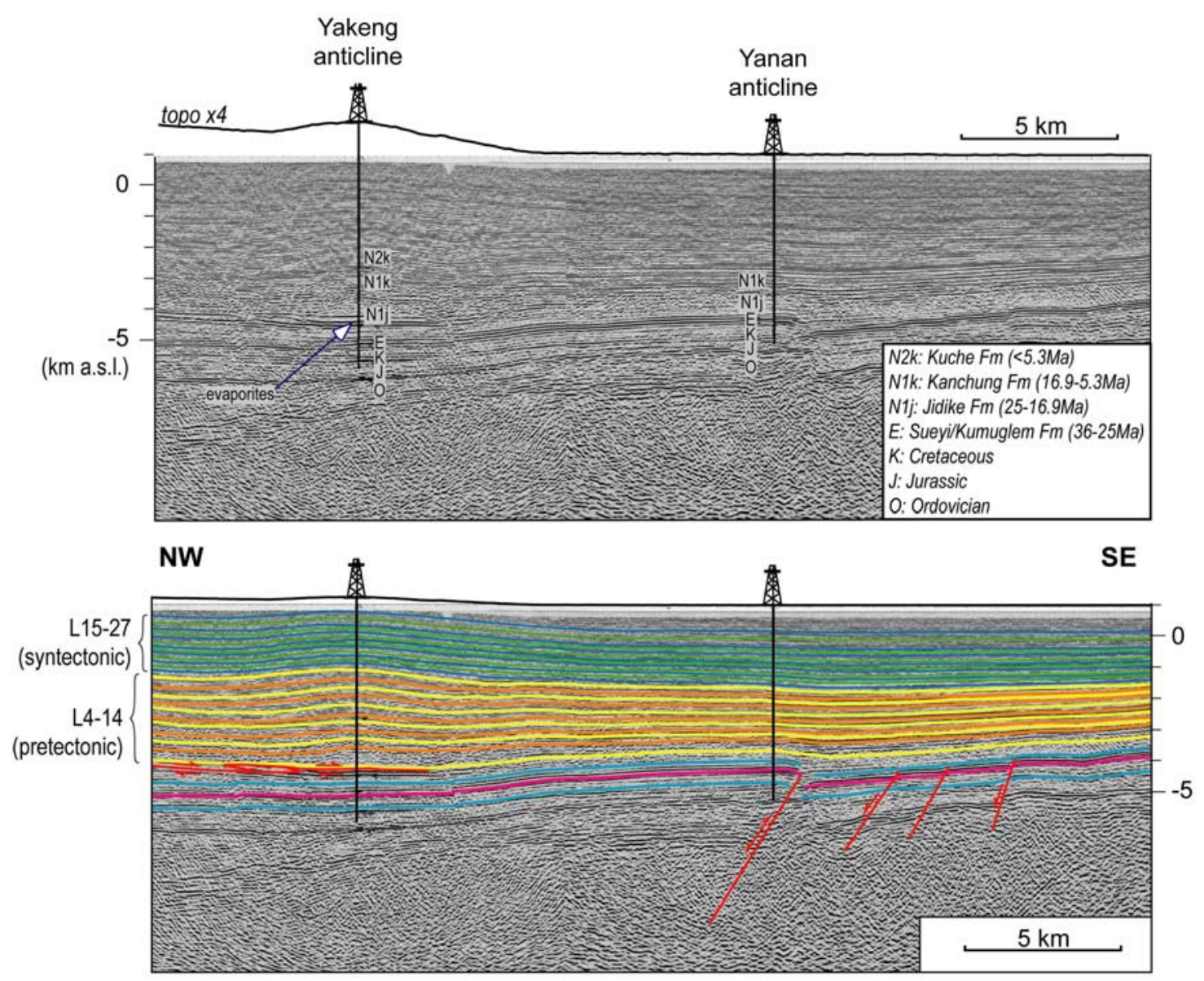

Figure 6. Seismic data and interpretation of Yakeng fold, from Hubert-Ferrari et al. [2005]. Layers L4 to L14 (orange and yellow lines) predate fold initiation, and L15-27 (green and blue) are syntectonic [Hubert-Ferrari et al., 2005; Gonzalez-Mieres and Suppe, 2006].

slopes, all consistent with basinward thinning of alluvial deposits. The 13 sets of depth residuals $(\mathrm{dZ})$ are then aggregated into one set of $(\mathrm{X}, \mathrm{dZ})$ values, which reflects invariant slope increase across the fold, and the aggregated set is fit using a single second-order polynomial, noted PF (Figure $7 \mathrm{~b}$ ). The initial geometry of each reflector $\mathrm{Li}$ is then approximated as the sum of the corresponding linear fit LFi and the common parabolic fit PF (Figure 7c). This ensures that individual thickness variations and upstream steepening are consistent with those observed, while avoiding unrealistic thickness disparities from one layer to the other in the core zone. The resulting set of fits, noted U15 to U27, is then used in our model to represent the initial geometries of the syntectonic reflectors.

[14] We then quantify the cumulative shortening of reflectors L15 to L27 using the excess relief area method of Epard and Groshong [1993]. Figure 8 shows the resulting amounts of shortening. Assuming a $0.43 \mathrm{~mm} / \mathrm{yr}$ sedimentation rate [Charreau et al., 2006], a linear fit of shortening versus depth is consistent with an average shortening rate of $\sim 0.14 \mathrm{~mm} / \mathrm{yr}$ over a period extending from $\sim 5.8$ to $2.1 \mathrm{Ma}$. The observed scatter is likely due to the approximation of our simplified initial geometry, and possibly to the uncertainties of the seismic reflection data. The regression plotted in Figure 8 is then used to define the amounts of shortening ascribed to each syntectonic reflec- tor, with an uncertainty of $\pm 70 \mathrm{~m}$ (dashed lines). For comparison, using the same sedimentation rate, the analysis by Hubert-Ferrari et al. [2007] of thickness variations in the same syntectonic layers yields a similar shortening rate of $0.12-0.13 \mathrm{~mm} / \mathrm{yr}$. Although such a thickness domain study arguably offers a finer analysis of the cumulative folding of each reflector, it fails to provide realistic original geometries of these markers.

[15] On the basis of these initial geometries, and on the respective amounts of shortening estimated above, it is now possible to adjust parameters of the displacement field model so that predicted finite geometries of L15-27 fit seismic observations. The model we use here is outlined in Appendix A (for a more in-depth description and discussion, see Bernard et al. [2007]). In such a model, for a given depth of the basal detachment and a given amount of shortening across the fold, the displacement field is entirely defined by the positions of an arbitrary number (n) of passive hinge lines, and by $\mathrm{n}-2$ scalar parameters, labeled $\alpha$, which characterize the spatial variation of uplift within each hinge-bounded zone. In order to fit these parameters, we define a rough initial set of $n=4$ hinge lines. The first and last of these hinges delimit the area where there is significant separation between the assumed initial geometries of seismic markers and their observed finite geometries. Then we adjust the values of the $\alpha$ parameters in the 
A

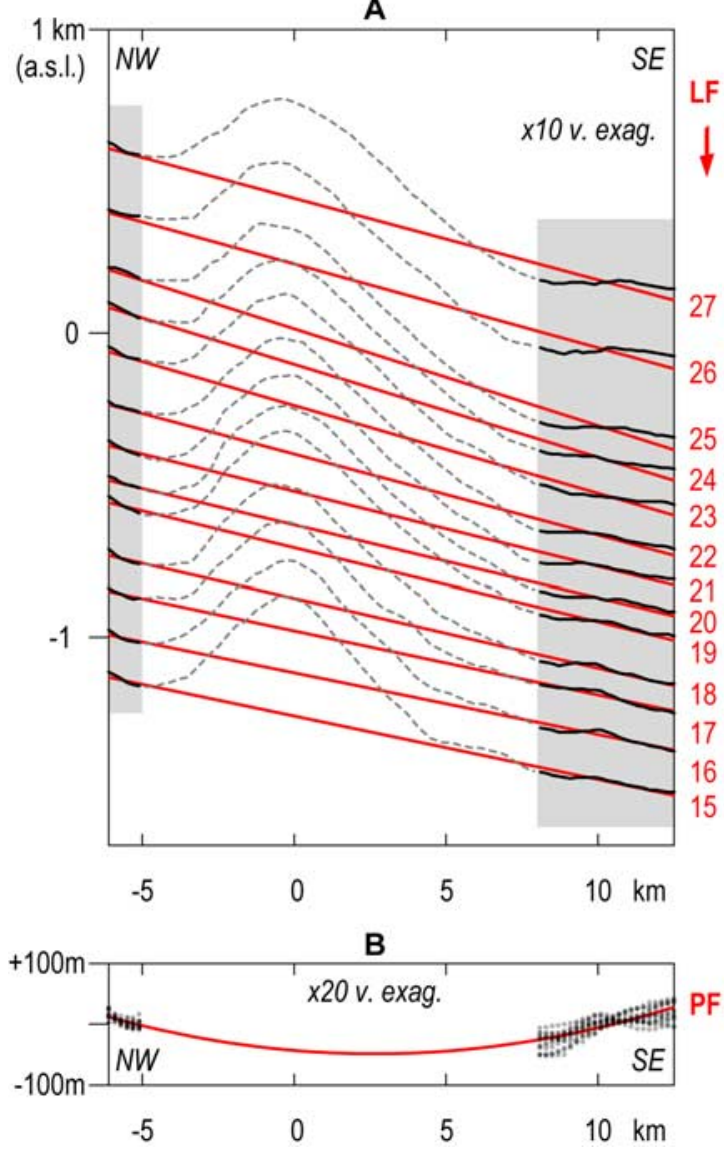

C

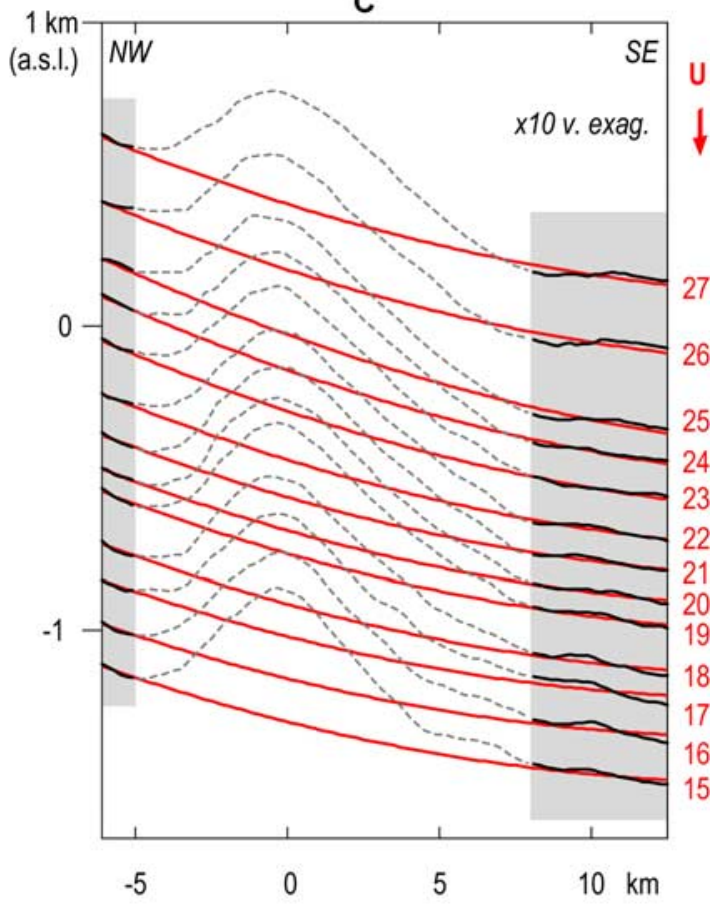

$U_{i}=L F_{i}+P F$

Figure 7. Regression of the original geometry of syntectonic seismic markers across Yakeng anticline. (a) First, the observed modern geometries away from the fold (solid black lines in gray boxes) are individually fit to their linear trends (LF15 to LF27, solid red lines). (b) The residuals of these linear fits are then binned together (gray dots) and fit using a single second-order polynomial (PF, solid red line). (c) The undeformed geometry of each seismic marker [i], noted Ui (solid red lines) is then approximated by the sum of its individual linear trend (LFi) and of the common curvature function (PF).

first and last hinge-bounded zones, so as to fit the finite tilt of the markers in the outmost areas of each limb. This requires modeling different amounts of cumulative shortening (one distinct value per marker), consistent with the amounts estimated above (Figure 8), which is done incrementally, in steps of less than $10 \mathrm{~m}$. Once the two initial $\alpha$ parameters are fit, we iterate the process, defining two new hinge lines and two corresponding $\alpha$ values, progressively fitting areas of the fold which lie closer to the core.

[16] In the case of the Yakeng anticline, the fold's subsurface width does not decrease significantly with depth, suggesting that the folding pattern is self-similar in cross section, as described by Hubert-Ferrari et al. [2007]. For this reason, here we use vertical hinge lines to parameterize the displacement model. While it is possible to obtain an approximate fit of the geometries of L15-27 using a sevenhinge model, the resulting parameters are heavily influenced by the bulge in the shapes of L15-19 south of the fold, which probably reflects an inherited geometry. Moreover, the L27 geometry predicted by this model is somewhat approximate. Since L27 is remarkably similar in shape to the topography of $\mathrm{Ta}$, we opted to use a set of parameters which closely fit L27 at the expense of a lower-quality fit to the deepest syntectonic markers (Figure 9). This model was

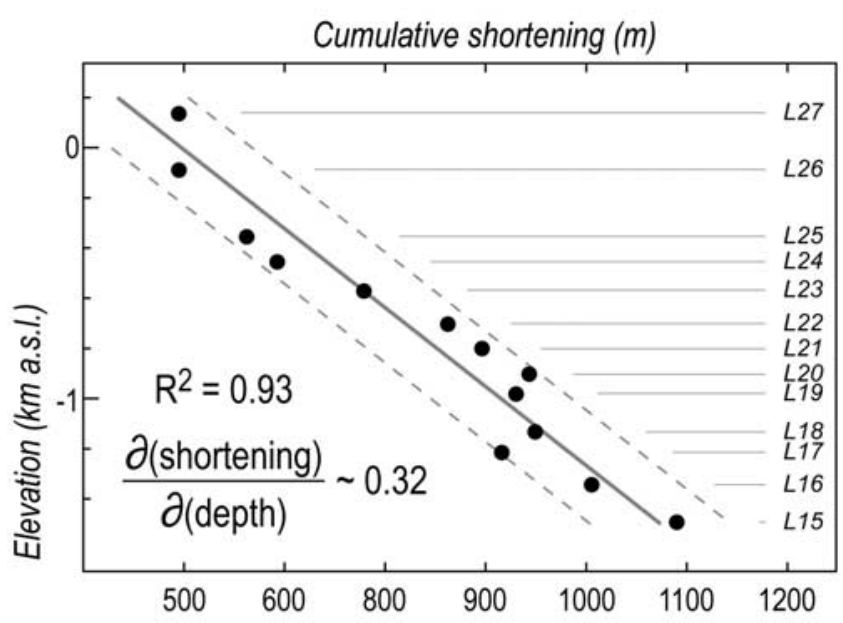

Figure 8. Yakeng shortening history recorded by syntectonic seismic markers. Cumulative shortening decreases linearly from 1.1 to $0.6 \mathrm{~km}$ between L15 (1.5 km bsl) and L27 $(0.1 \mathrm{~km}$ asl). On the basis of the $0.43 \mathrm{~mm} / \mathrm{yr}$ sedimentation rate of Charreau [2005], this is consistent with an average shortening rate of $0.14 \mathrm{~mm} / \mathrm{yr}$ over $\sim 3.7 \mathrm{Ma}$. 


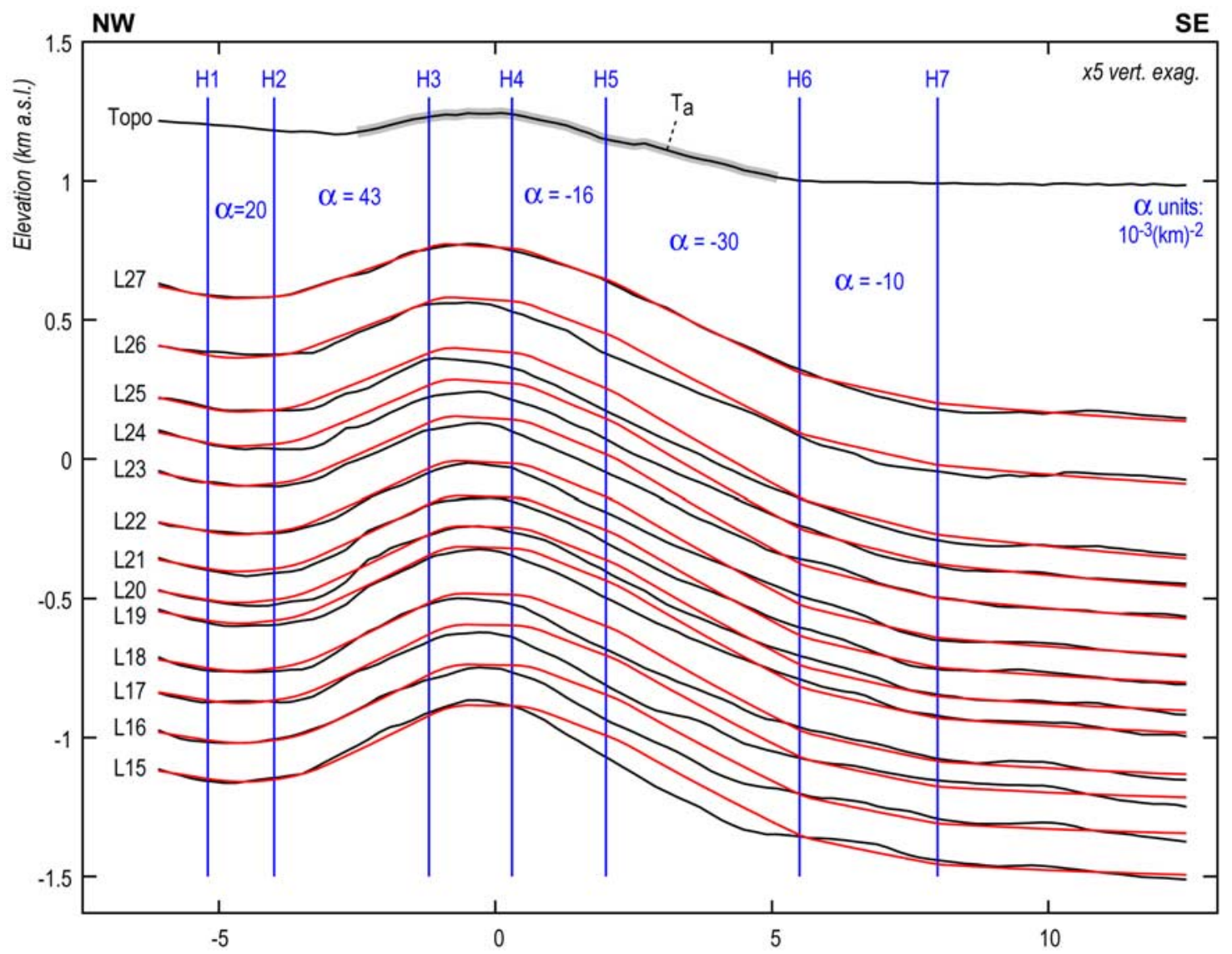

Figure 9. Parameters (in blue) of Yakeng deformation model. Black lines mark topography and observed seismic markers L15 to L27. Red lines mark the model-predicted geometry of markers, assuming the initial geometry shown in Figure 7, and a constant shortening rate predicted by the linear regression of Figure 8. We elected to primarily fit L27 rather than the more disturbed deeper markers (discussed in text).

then used to estimate the initial geometries and cumulative shortening of the geomorphic markers.

\subsection{Geomorphic Record of Cumulative Shortening}

[17] Our model allows predicting the slope acquired after an arbitrary amount of deformation, so we can use this prediction to estimate the shortening and local uplift experienced by the geomorphic surfaces Ta and Tf. We have no precise a priori information on their respective initial elevations. We can, however, place realistic constraints on their initial slopes.

[18] The initial, undeformed geometry of the partially preserved fluvial terrace Tf must reflect that of the paleoriver. We infer that its original slope lies somewhere between the local slope of the modern East Quilitag river below $\mathrm{Tf}(1.3 \%)$ and the average slope along the whole length of the gorge across the fold (1.6\%). Considering an initial marker with such a dip angle, we systematically vary its initial elevation and the amount of shortening it recorded, using the deformation model determined above, and compare the predicted elevation and dip to those of Tf. For an initial slope of $1.3 \%$, between 55 and $65 \mathrm{~m}$ of shortening are necessary to tilt and uplift the initial marker so that the deformed geometry fits the observed geometry of Tf (Figure 10). This corresponds to an initial elevation
20-26 m below the modern-day river, and to $\sim 40 \mathrm{~m}$ of local uplift. For a steeper initial dip of $1.6 \%$, the modeled amount of shortening is $75-85 \mathrm{~m}$, with an initial level $33-$ $40 \mathrm{~m}$ below the modern-day river, corresponding to over $50 \mathrm{~m}$ of local uplift. Note that the modeled local uplifts are significantly larger than the apparent uplift of $\sim 17 \mathrm{~m}$, because the modern-day river runs at a higher elevation than that when Tf was formed, presumably because of ongoing sedimentation downstream and upstream of the fold.

[19] Estimating the original slope of the alluvial terrace $\mathrm{Ta}$ is somewhat less straightforward. It could be argued that, as an alluvial terrace similar to the youngest seismic markers (L27 and below), its initial profile should resemble U27, that of L27. However, modeling the incremental folding of such a marker (parallel to U27 but with appropriate initial elevation), results in a predicted profile higher than the actual topography on the north flank of the fold, and lower on the south flank (Figure 11a). This suggests that the assumed initial geometry dips too steeply to the south.

[20] Alternatively, Ta was likely emplaced as the paleosurface of a fan fed to the East Quilitag river, similar to the modern dark grey fan upstream of the anticline (see Figure 4). However, the original slope of such a terrace is not precisely measurable. In order to overcome this uncer- 


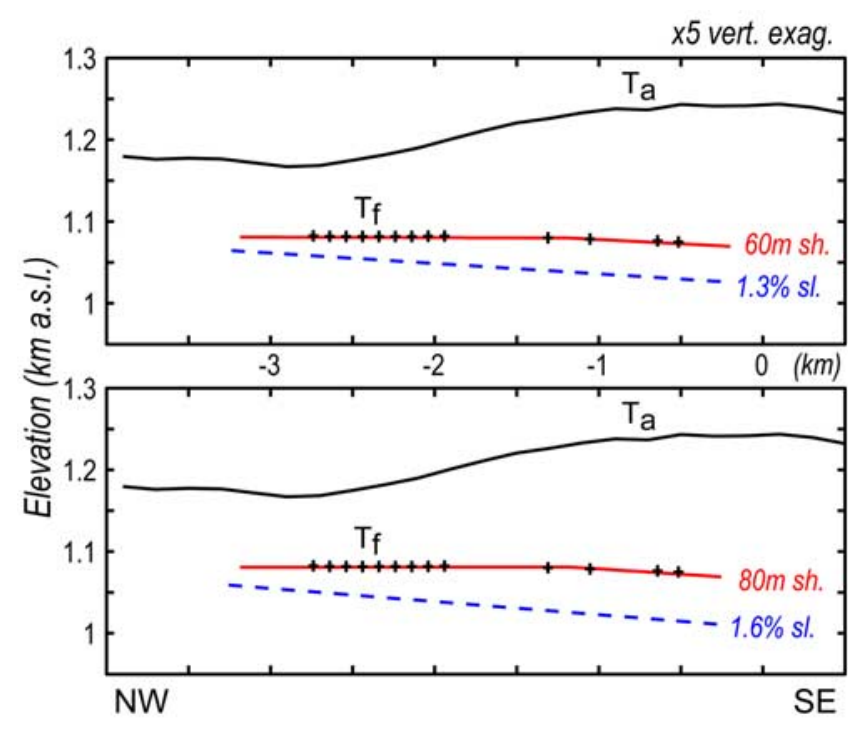

Figure 10. Models of deformed fluvial terrace Tf across Yakeng fold. Depending on the initial slope of the river terrace ( 1.3 to $1.6 \%$, dashed blue, discussed in text), the amount of shortening necessary to deform it into its presentday geometry (black crosshairs) varies from $60 \pm 5 \mathrm{~m}$ to $80 \pm 5 \mathrm{~m}$. Red lines plot the predicted Tf geometry. Black lines show projected profile of topography, including north limb of alluvial terrace Ta.

tainty, one can reverse the modeling approach used above, by progressively retro-deforming the modern profile of $\mathrm{Ta}$ until it is restored to a straight line (Figure 11b), thus jointly determining the cumulative amount of shortening and the original slope of Ta. This assumes that, at a scale of $\sim 7 \mathrm{~km}$, the concavity of Ta's original profile is negligible compared to the modern relief noise and the uncertainties of the folding model. Since the optimization of such a linear fit is sensitive to local topographic irregularities, we considered the modern Ta profile obtained by stacking nodes from a Shuttle Radar Topography Mission (SRTM) digital elevation model (DEM) (3" resolution). Around $320 \mathrm{~m}$ of cumulative shortening are required to minimize the misfit between the retro-deformed profiles and their respective linear trends, obtained by least squares fitting. The corresponding initial slope, $\sim 1.3 \%$, is consistent with the modern-day slopes of the river channel where Tf was emplaced (see Figure 10), and roughly parallel to the distal part of the modern East Quilitag fan, upstream from the fold. Testing the validity of the predicted original slope of Ta will likely require additional seismic data in the shallow syntectonic section. At this stage, it is difficult to assign confidence bounds on the estimated cumulative shortening recorded by $\mathrm{Ta}$, but its estimated value, on the order of $320 \mathrm{~m}$, appears quite robust, based on the various scenarios we attempted to model.

\subsection{Growth of the Yakeng Fold and Its Influence on Drainage and Sedimentation}

[21] Our modeling of the Yakeng anticline highlights the importance of accurately estimating the initial geometry of folded geomorphic markers. Assuming that ongoing deformation is similar to the finite folding, the present-day shape of the Yakeng ridge appears to put tight constraints on the original slope of Ta (Figure 11). Rather than an artifact of our particular model, this is a general consequence of the self-similarity of deformed markers noted by HubertFerrari et al. [2007]. Further work is now needed to test this prediction by direct observation, possibly through shallow seismic imaging.

[22] Whatever the precise original geometry of $\mathrm{Ta}$, it seems unavoidable that its initial slope was much shallower than that of L27, the youngest continuous seismic reflector. A tentative explanation to the discrepancy might be that seismic reflectors beneath Yakeng experienced some tilting as a result of the growth of the Quilitag anticline [HubertFerrari et al., 2007]. If this is the case, whether tilting occurred prior to or during the development of Yakeng does not affect our analysis, provided that the assumed initial geometries correctly reflect the effect of Quilitag folding.

[23] The current geometry of Tf and Ta imply that since their emplacement they recorded cumulative shortening on the order of 70 and $300 \mathrm{~m}$, respectively. In theory, provided some knowledge of the sedimentation rate, one could

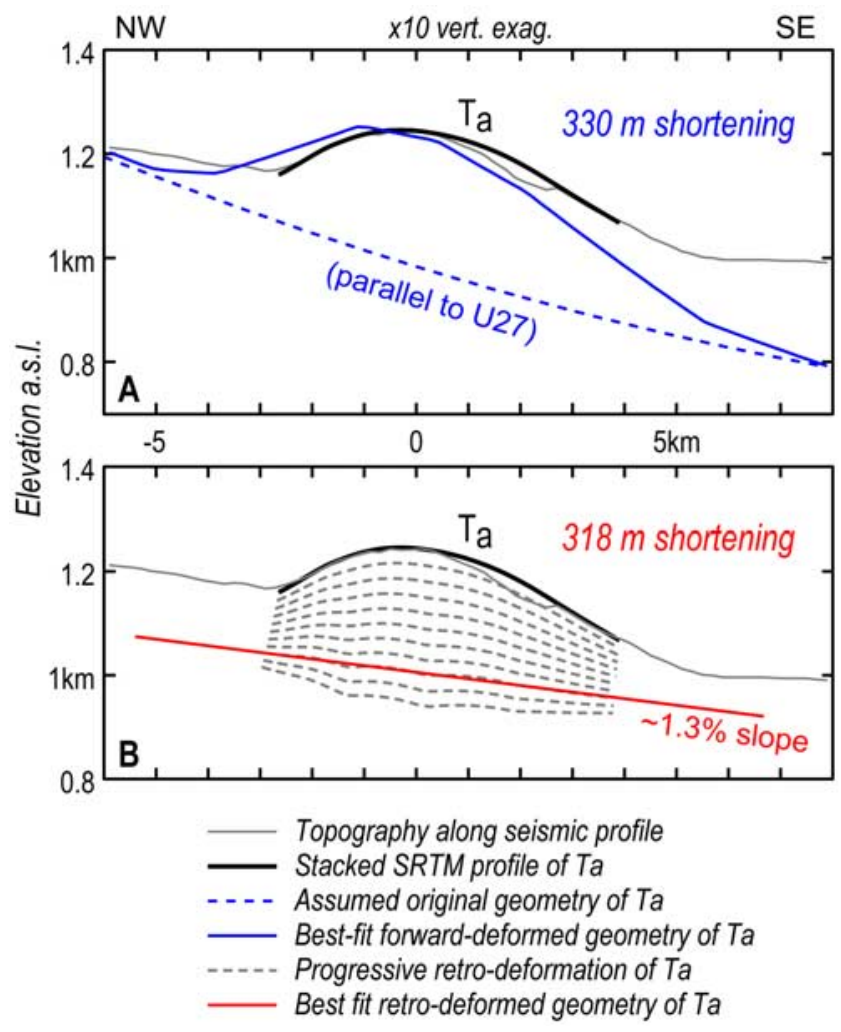

Figure 11. Models of deformed alluvial terrace Ta across Yakeng fold. (a) Best fitting model assuming a (dashed blue) initial geometry of Ta parallel to that of L27. Predicted geometry differs significantly from observed shape of Ta. (b) Retro-deformation of Ta (profile obtained by stacking $3^{\prime \prime}$ resolution SRTM DEM). $318 \mathrm{~m}$ of cumulative shortening minimize misfit between retro-deformed geometries of $\mathrm{Ta}$ and a straight line. Each stage of the retro-deformation (dashed gray lines) shown here corresponds to a step of $40 \mathrm{~m}$ of shortening. Predicted original slope is similar to that of the modern river. Note that sequence of post-Ta sediments upstream of fold is significantly thicker than downstream. 


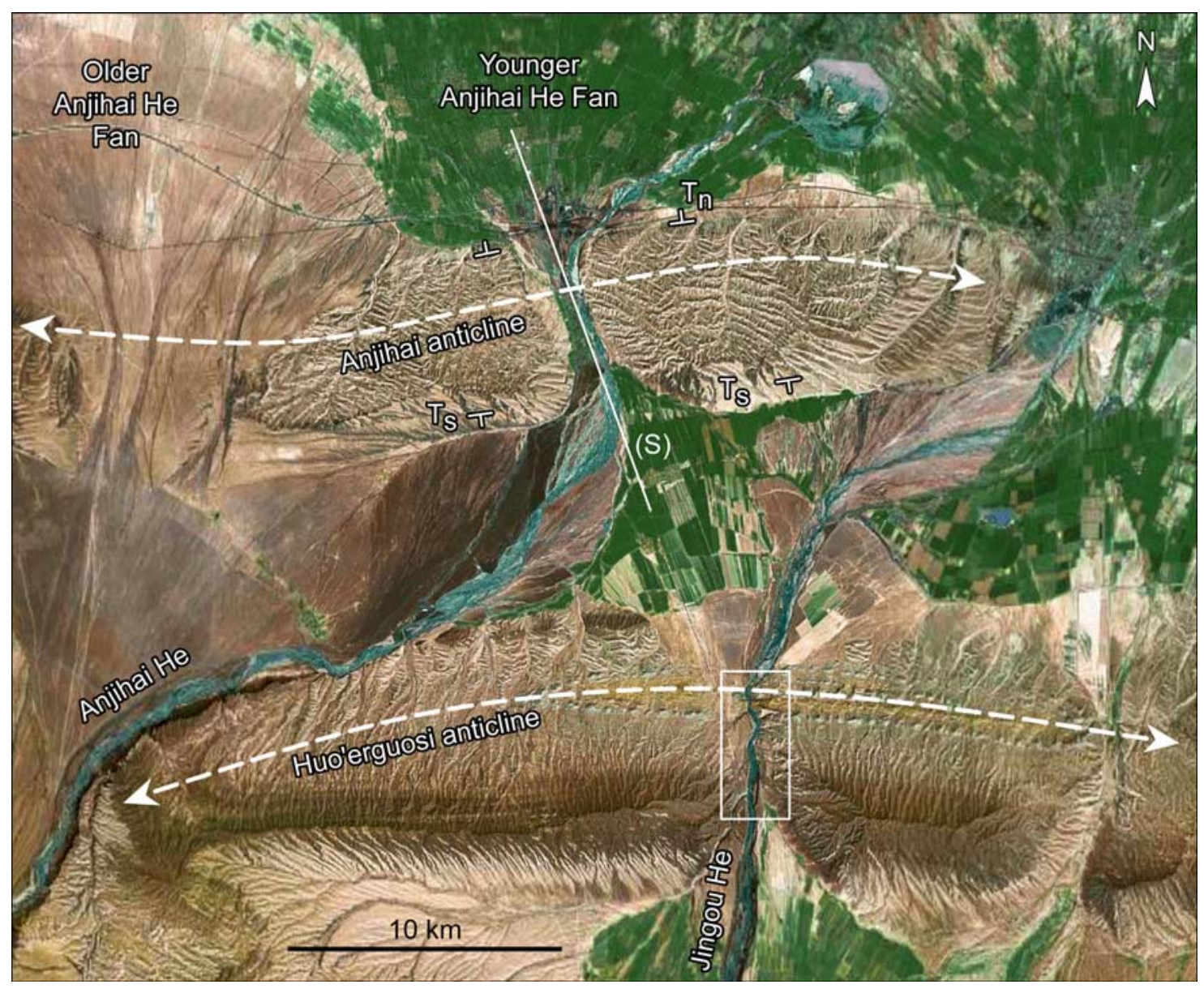

Figure 12. Map of Anjihai. Solid white line (S) marks location of seismic profile [He et al., 2005]. White "T" marks indicate dips of abrasion terraces Tn and Ts. White box shows the location of magnetostratigraphic section of Charreau [2005] across Huo'erguosi anticline.

deduce their ages from their reconstructed initial geometries. However, if indeed the slope of Ta is similar to that predicted in Figure 11c, the thickness of post-Ta sediments upstream of the fold is about twice as thick as downstream of it, which could be readily interpreted as resulting from emergence of relief, the ridge acting as a dam. Such a hydrographic disruption would likely perturb the constant sedimentation regime documented by Charreau et al. [2006]. The Yaha sedimentation rate is thus not a reliable indicator of the ages of alluvial surfaces which were formed after topographic emergence of the Yakeng ridge, including $\mathrm{Ta}$. Age constraints on Ta and Tf should thus be obtained through direct dating methods (OSL, cosmogenic isotopes), and their reconstructed depths can only provide very loose age constraints. Accordingly, if we assume that the sedimentation rate was mostly perturbed upstream of the fold, the reconstructed position of Ta downstream of the fold ( $\sim 65 \mathrm{~m}$ below the surface, see Figure $11 \mathrm{~b}$ ) would be consistent with an age on the order of $150 \mathrm{kyr}$. This estimate would correspond to an average post-Ta shortening rate of about $2.1 \mathrm{~mm} / \mathrm{yr}$, about fifteen times faster than the longerterm rate $(0.14 \mathrm{~mm} / \mathrm{yr}$, see Figure 8$)$. Conversely, assuming a current shortening at a rate comparable to the long-term average would yield ages for Tf and Ta of $500 \mathrm{kyr}$ and more than $2 \mathrm{Myr}$, respectively, at odds with the available geo- morphic evidence. The shortening across Yakeng has thus necessarily accelerated significantly in geologically recent times, although better quantifying the modern rate will require direct dating of $\mathrm{Tf}$ and $\mathrm{Ta}$.

\section{Anjihai}

\subsection{Surface Expression and Finite Shortening}

[24] The Anjihai anticline lies frontmost in the fold-andthrust belt along the northern Tien Shan piedmont (Figures 2 and 12). The surface fold is about $7 \mathrm{~km}$ wide, and exposes conglomerates of the Xiyu (highly diachronous, Neogene to Quaternary) and Dushanzi (Neogene) formations, unconformably overlain by Quaternary conglomerates and loess (Figure 13). On the flanks of the anticline, such Quaternary structural surfaces are well preserved, forming triangular cuestas with slopes of $7-10 \%$. We interpret these surfaces (noted $\mathrm{Tn}$ and $\mathrm{Ts}$ ) as folded strath terraces (green line segments in Figures 13 and 14), dating back to a time when the erosion power of the Anjihai He and/or Jingou He rivers was strong enough to remove emergent relief as the fold was growing. The abrasion terraces were later abandoned and started passively recording deformation. This was likely coeval with entrenchment of a river channel across the fold, originally by the Jingou $\mathrm{He}$ and today by the Anjihai He. 

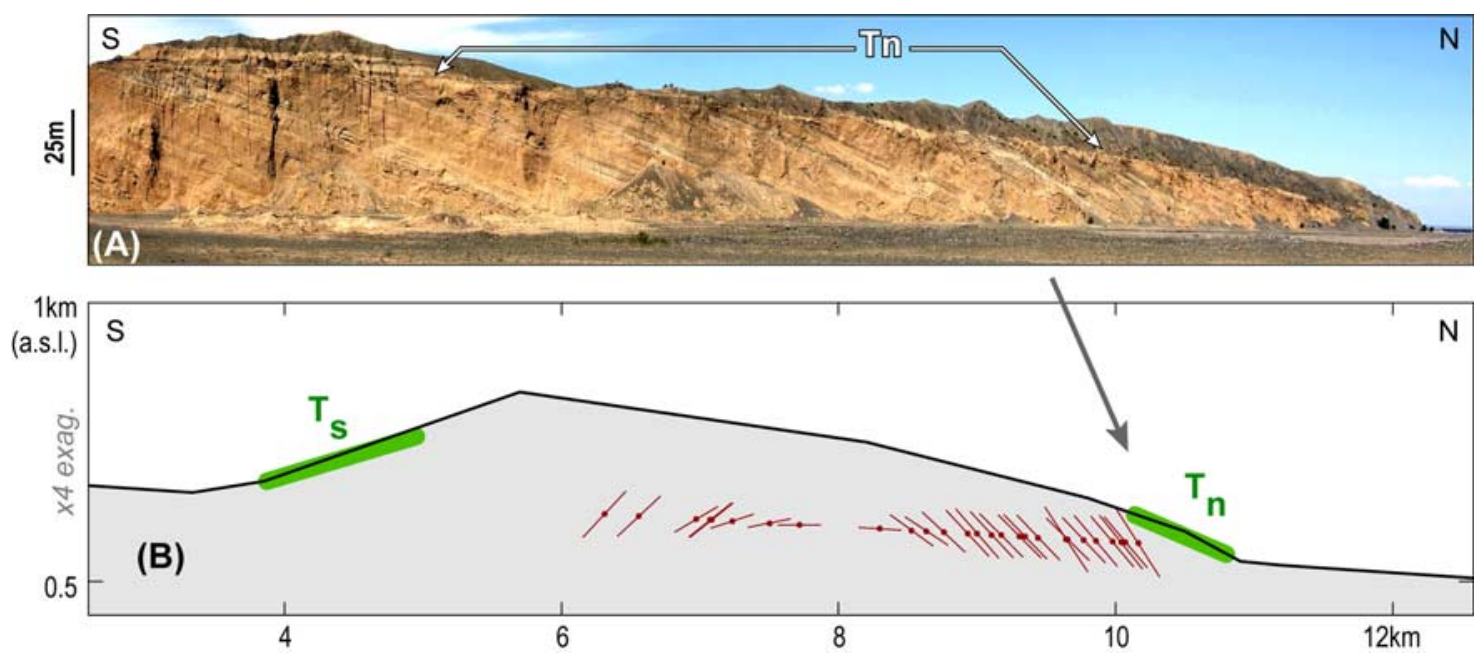

Figure 13. Geomorphic record of folding at Anjihai. (a) Mirror-inverted east looking field photograph of loess-covered, alluvial strath terrace Tn, unconformably overlying older alluvial gravel fanglomerates exposed by fluvial incision. (b) Sketch of available surface records of folding. Topographic profile is outlined in black. Green segments mark positions of well-preserved strath terraces Tn and Ts. Red lines indicate projected dips of surface structural measurements.

Along the steep walls of the river gap, the shallow structure of the fold is beautifully exposed, with dip angles up to $25^{\circ}$ (Figure 13).

[25] The seismic profile run along the Anjihai river (Figure 14) reveals a smooth, rather symmetric subsurface structure consistent with detachment-driven folding. Although the lower part of the section, $\sim 3 \mathrm{~km}$ below sea level (bsl), might be suggestive of small-scale ramping near the fold's core, we find it unlikely that such structures would have significant effects at the scale of our study. For one thing, the small size of these ramps precludes them from having absorbed large amounts of slip. Moreover, they lie deep enough that any resulting perturbation of pattern of folding should not extend to the surface and shallow subsurface, thus to the stratigraphic and geomorphic evidence relevant to this study.

[26] The Anjihai seismic data were only made available in double-time domain, and we performed a first-order conversion to depths using a uniform seismic velocity of $2.5 \mathrm{~km} / \mathrm{s}$. While this is probably an unrealistic approximation, different competing assumptions on the velocity structure of the fold (lithology- versus compaction-driven velocities) would yield different depth-converted sections and affect our analysis. For now, we use this crude depth correction, not so much as a reliable indication of the fold's deeper geometry, but as a starting point to demonstrate the potential of our approach.

[27] Our line drawing interpretation of the seismic data (Figure 14) allows mapping 7 distinct markers across the fold (L1 to L7). These markers are linear away from the fold, making it straightforward to infer their original, undeformed geometry. For all seven markers, the structural relief areas are well correlated with depth, consistent with $\sim 1.5 \mathrm{~km}$ of finite shortening over a basal detachment located $\sim 5 \mathrm{~km}$ below the surface $(4.5 \mathrm{~km} \mathrm{bsl}$, see Figure 15). We conclude that the sediments below L7 are pretectonic strata, which yields a lower stratigraphic bound for the initiation of folding, $2.0 \mathrm{~km}$ below the surface. This depth corresponds to an age of $7.4 \mathrm{Ma}$, according to the $0.27 \mathrm{~mm} / \mathrm{yr}$ sedimentation rate derived form the magnetostratigraphies of Charreau et al. [2005] and Charreau [2005].

\subsection{Parameters of the Deformation Model}

[28] Imposing a finite shortening of $1.55 \mathrm{~km}$ and a basal detachment depth of $4.5 \mathrm{~km}$ bsl, we can model the observed finite geometry of the pretectonic markers using the fold kinematics discussed in Appendix A. A good fit of the seismic data is obtained with 12 hinge-bounded domains (Figure 16). The agreement between the predicted and observed dip angles is shown in Figure 17, where all present-day seismic reflectors were retro-deformed according to our best fitting model parameters. Below L7, the retro-deformed reflectors are uniformly flat, whereas above L7 they adopt a syncline-like geometry, implying that the actual amount of shortening experienced by these markers is smaller than the finite amount. These reflectors must therefore correspond to growth strata.

\subsection{Early Shortening History and Evidence for Quaternary Acceleration}

[29] In order to account for the progressive emplacement and shortening of the seismic reflectors above L7, we tested simple scenarios of shortening, by postulating a constant shortening rate, a constant sedimentation rate, and by varying the stratigraphic level of fold initiation. We could obtain a good fit to the seismic data from this approach (Figure 18). However, all of these models predict that the fold should have no or negligible topographic relief, because the sedimentation rate, well-constrained to $\sim 0.27 \mathrm{~mm} / \mathrm{yr}$ by Charreau [2005], generally exceeds the uplift rate. It is thus impossible to reproduce the structural dip angles observed along the cliff incised by the Anjihai $\mathrm{He}$ river, because the model does not allow for a cliff to form. This is clear indication that the ratio of shortening to sedimentation rates has recently increased. Nevertheless, the geometry of seismic reflectors above L7 supports early 

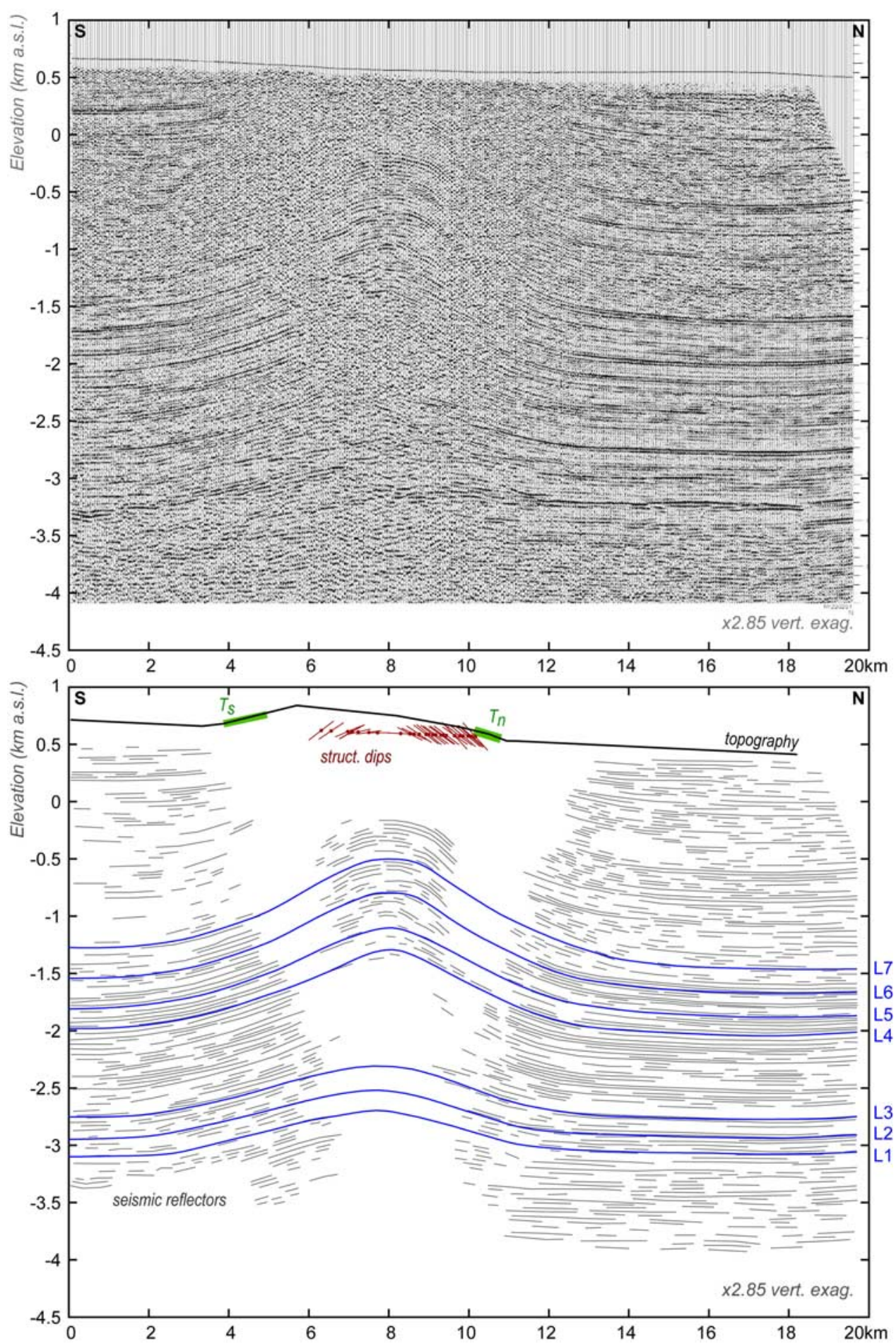

Figure 14. Seismic profile across Anjihai [He et al., 2005] and our line drawing interpretation (gray segments). Seven continuous reflectors (blue lines L1 to L7) can be mapped across the fold.

initiation of folding, albeit with average rates no faster than $0.4 \mathrm{~mm} / \mathrm{yr}$ between the deposition of L7 and that of the shallowest seismic reflectors (from $1.25 \mathrm{~km}$ bsl to $0.5 \mathrm{~km}$ above sea level (asl), i.e., roughly from 7.4 to $0.9 \mathrm{Ma}$ ).

[30] The shallowest seismic reflectors are too deep to have unambiguously recorded any recent acceleration of shortening. In the absence of well-preserved fluvial terraces across the fold, the only available geomorphic markers are the alluvial strath terraces Tn and Ts. It is possible that these surfaces were originally connected, forming one continuous terrace tread $\mathrm{Ta}$ across the fold. Alternatively, Tn and Ts could correspond to distinct stages of alluvial erosion, possibly driven by the complex capture history of the Jingou He/Anjihai He system [Poisson, 2002].

[31] Unfortunately, the original depth and slope of Tn, Ts, and the hypothetical Ta are unconstrained. Using the same 


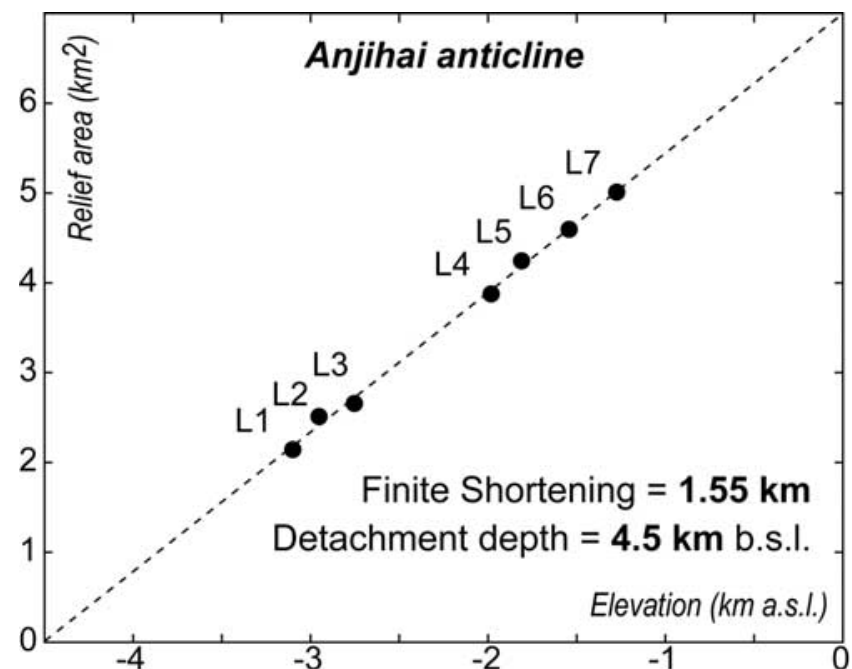

Figure 15. Plot of excess area versus stratigraphic depth for Anjihai fold. Linear fit corresponds to $1.55 \mathrm{~km}$ of finite shortening.

kinematic deformation model as above, and assuming the initial slope of the terrace(s) was similar to that of the modern topography, roughly $500 \mathrm{~m}$ of shortening are necessary to fit the present geometry of Ts (Figure 19). However, in this scenario the predicted position of Ta does not coincide with Tn. Indeed, it is striking that, contrary to the Yakeng case, the structural axis of the anticline and the core of the topographic fold are not colocated. This precludes modeling $\mathrm{Tn}$ and Ts as a continuous surface originally emplaced parallel to the modern alluvial topography, and could result from various factors. For instance, the original slope of the hypothetical continuous terrace "Ta" might have been steeper that we assumed, although we did not find evidence supporting this hypothesis, neither in the geomorphic record nor in the shallowest section of the seismic profile. Alternatively, the discrepancy could be interpreted as evidence of a recent change in the pattern of deformation, corresponding to a southward migration of the locus of folding. However, there is again no supporting evidence of such a shift. A third hypothesis is that Ts has recorded a larger amount of cumulative shortening than $\mathrm{Tn}$, reflecting an older age. This would be consistent with a complex alluvial history, with successive episodes of abrasion and aggradation, probably related to the interplay between the Jingou He and Anjihai He fans [Poisson, 2002; Poisson and Avouac, 2004]. Discriminating between these hypotheses will likely require additional evidence such as direct dating of Tn and Ts and shallow seismic imaging of the limbs of the fold.

\subsection{Growth History of the Anjihai Fold}

[32] Although some aspects of the study should be reassessed once better depth constraints on the seismic

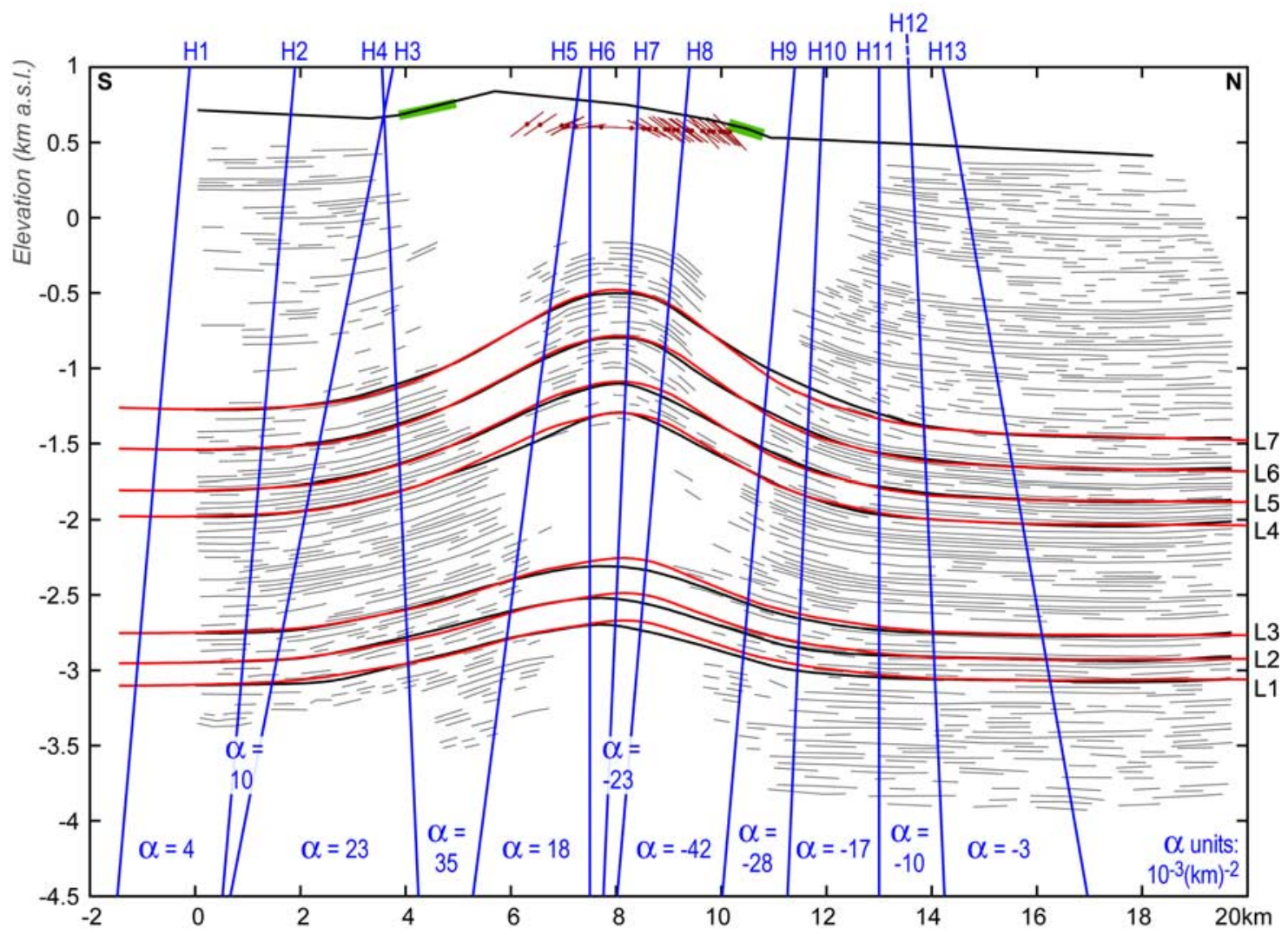

Figure 16. Parameters (in blue) of Anjihai deformation model. Black lines mark topography and observed continuous seismic reflectors L1 to L7. Red lines mark the model-predicted geometry of reflectors, using the finite shortening measured in Figure 15. Deeper X axis coincides with basal detachment deduced from area relief plot. 


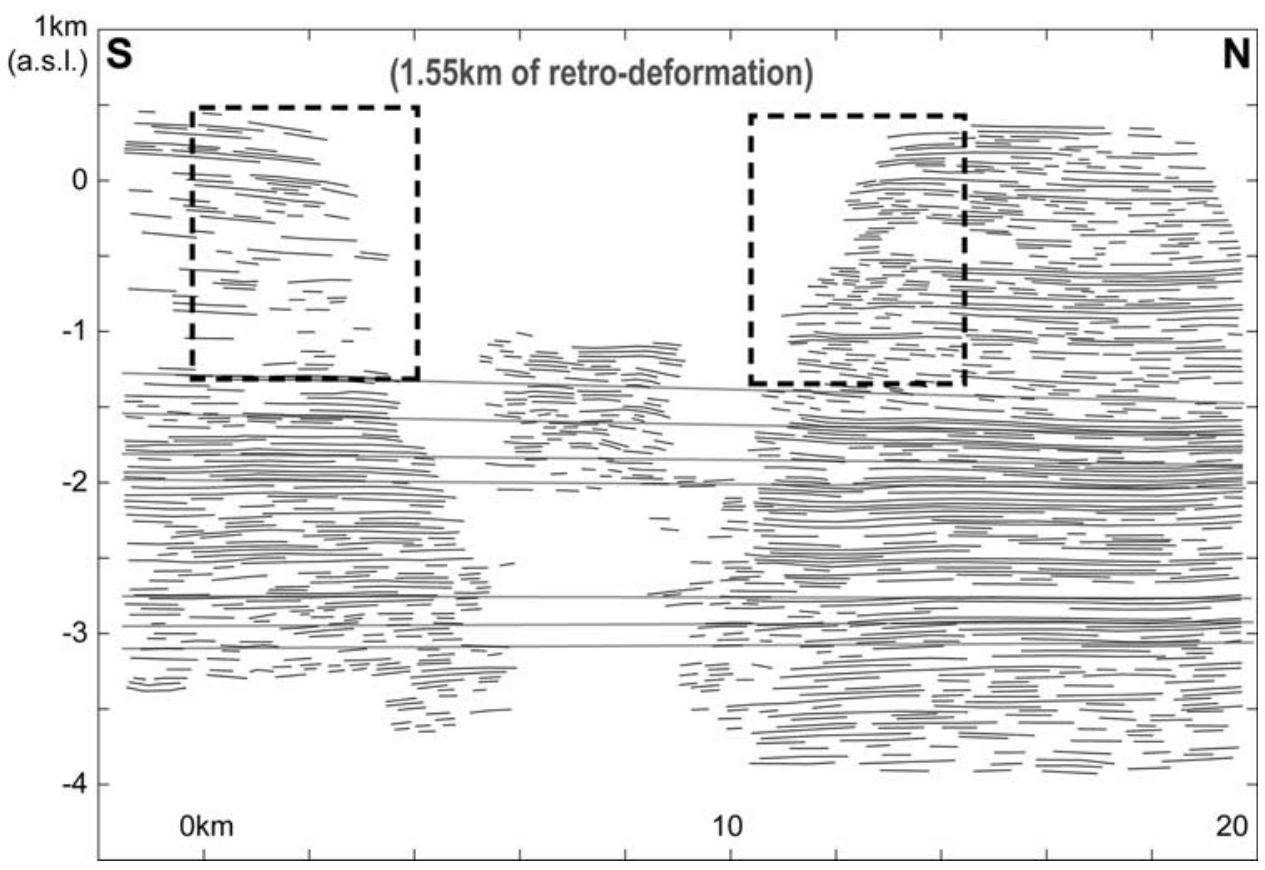

Figure 17. Anjihai seismic reflectors, retro-deformed using the parameters from Figure 16 and the finite shortening deduced from Figure 15. Shallow reflectors near fold core (dashed black boxes) have recorded only part of finite shortening, as evidenced by their retro-deformed dips.

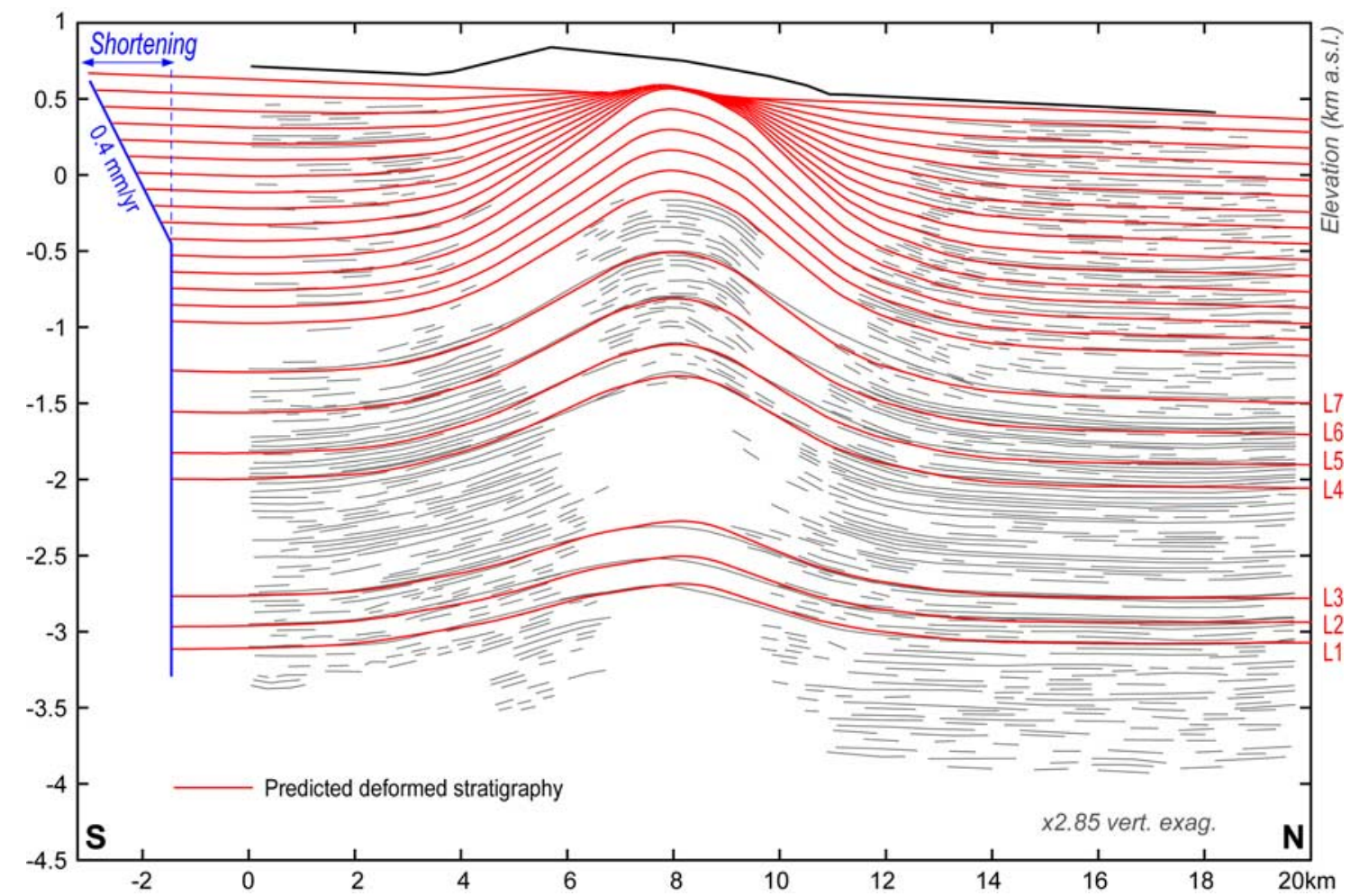

Figure 18. Predicted structure of Anjihai fold assuming a constant ratio of shortening versus sedimentation rates. This model predicts only negligible topographic relief, at odds with observed morphology. 


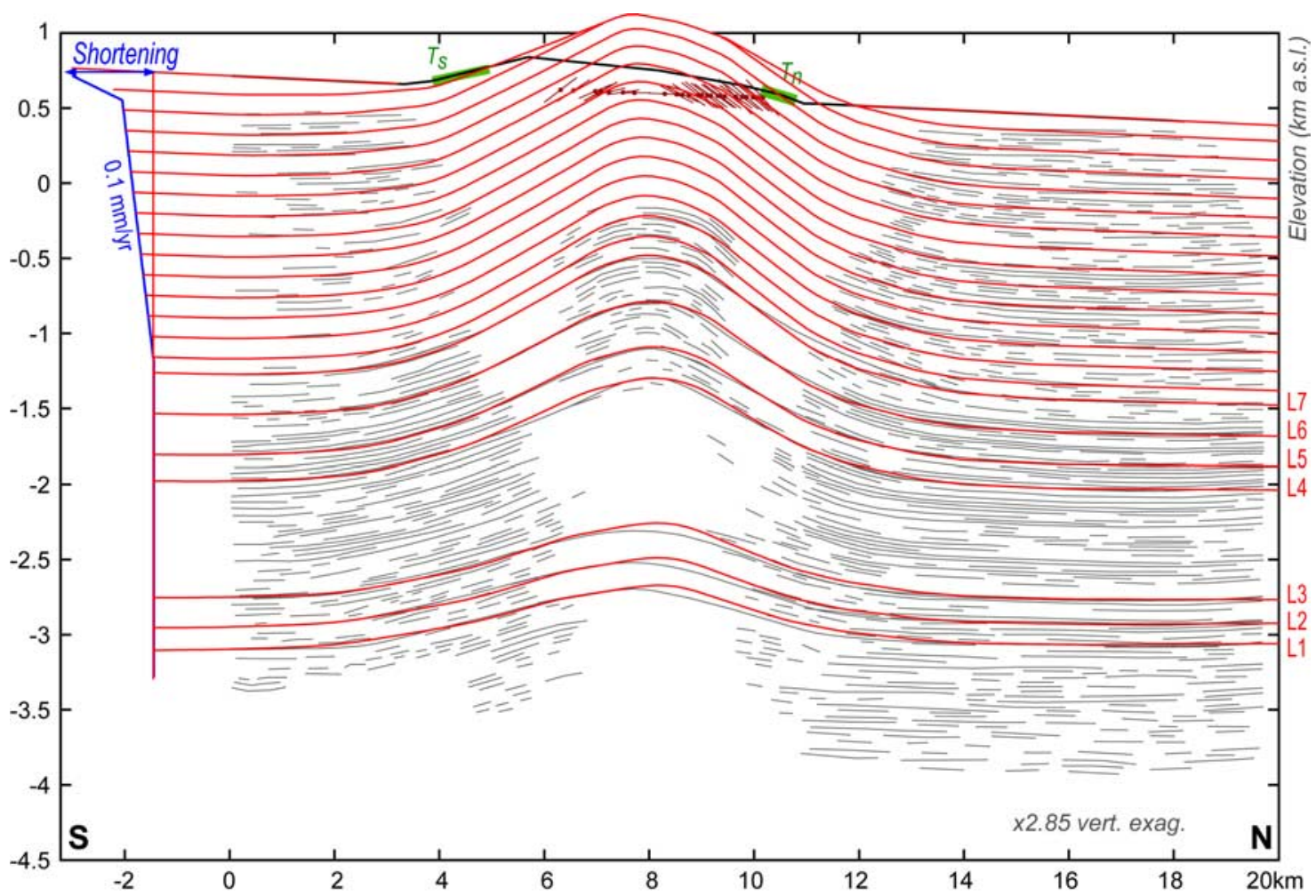

Figure 19. Predicted structure of Anjihai fold assuming a two-phase shortening history. This model fits the observed topography and structural dips but fails to model Tn and Ts as a single, coeval surface.

data and better chronological constraints become available, the first-order results of our model are not expected to depend qualitatively on a specific seismic velocity conversion. Building up the observed topography does require a recent acceleration of uplift, because the early rate of deformation recorded by syntectonic seismic reflectors is too slow to generate significant relief (Figure 18). Furthermore, the acceleration must predate the emplacement of $\mathrm{Tn}$ and $\mathrm{Ts}$, as evidenced by the abrasion of underlying units (Figure 13).

\section{Discussion}

\subsection{Hypothesis of a Stationary Pattern of Folding}

[33] The assumption that the finite pattern of folding is similar to the modern kinematics of an anticline is not generally true, particularly for "mature" folds whose deformation is likely to have developed in several distinct stages. Such an assumption, however, is more tenable a priori in the case of a fault tip fold, which may constitute the first stage of a folding process [e.g., Bernard et al., 2007]. In the two case examples presented above, there is no evidence that other folding processes account for a significant portion of the deformation. Although we cannot exclude that such competing types of folding exert a second-order kinematic influence or that the pattern of fault tip folding is not strictly invariant with time, such phenomena are not required to reproduce the structural and geomorphic evidence detailed in this study. In our opinion, the best way to test this assumption would be to reliably constrain the original geometry of a late
Pleistocene marker, including in the subsurface of the fold limbs, providing a geomorphic equivalent to the continuous structural markers used to calibrate the model's parameters.

\subsection{Competition Between Folding and Sedimentation}

[34] The study of these case examples highlights some simple interactions between folding, sedimentation and erosion, summarized in Figure 20. Topographic relief can only accrue where and when tectonic uplift is faster than sedimentation (see also discussion by Simoes et al. [2007b]). Thus, in the early phases of the histories of both folds, syntectonic sedimentary units extend continuously across the fold, and no topographic relief builds up (Figure 20a). As shortening rate increases, maximum uplift rates overcome the sedimentation rate, in a zone whose width is a function of the spatial distribution of uplift. As long as the hydrographic system has enough erosion power to sweep laterally back and forth and abrade rocks as they are uplifted, relief remains negligible, and an abrasion surface is emplaced, unconformably overlying older units (Figure 20b), as observed on the northern flank of Anjihai (Figure 13a). If the river is forced to entrench in a narrow gorge because it does not have enough stream power to abrade laterally all the uplifted rocks, relief starts building up above the core of the anticline (Figure 20c). Figure 21 shows a sketch summarizing the appearance of the fold at that stage, which corresponds to the current situation of Yakeng. Eventually, the fold ridge is expected to undergo secondary erosion driven by its own relief, as observed in the exposed core of Anjihai. 


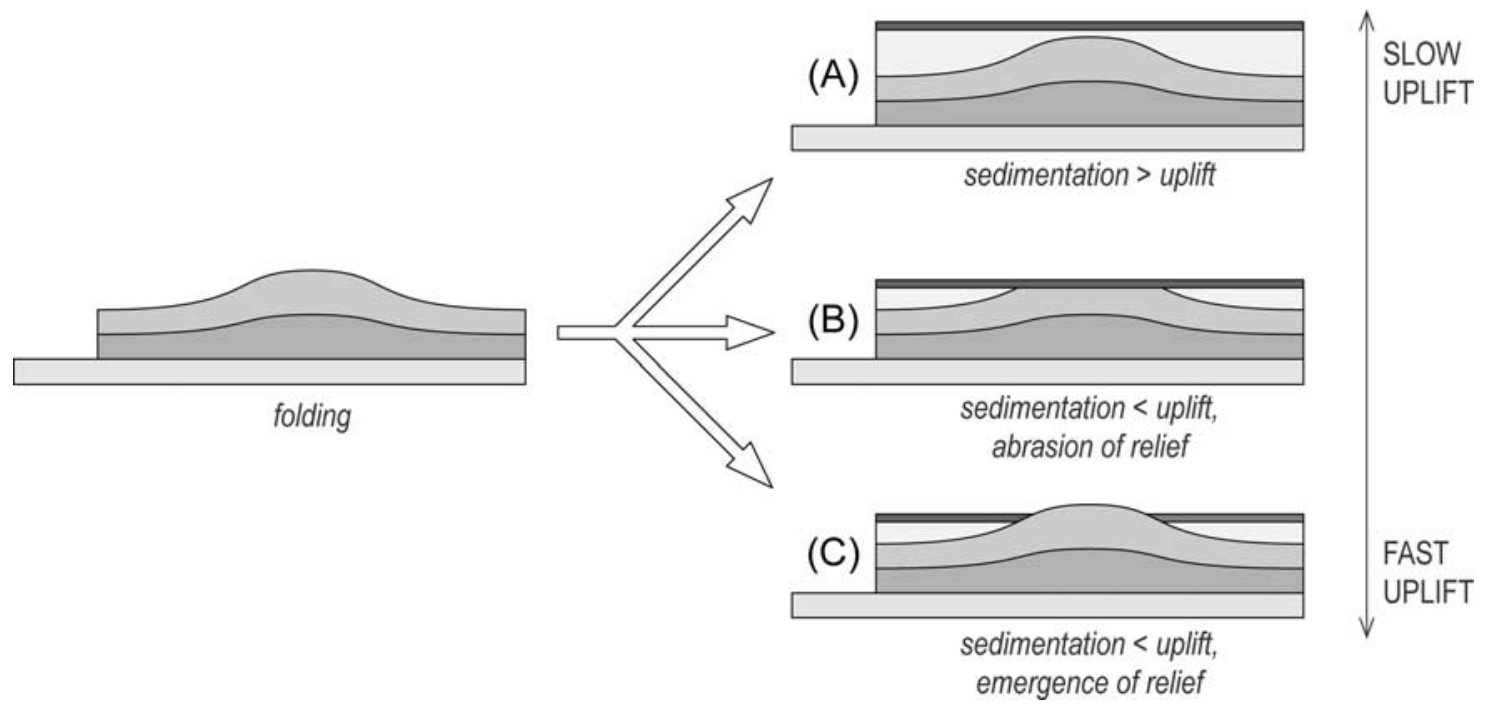

Figure 20. Summary of fold growth accounting for interactions between uplift, sedimentation, and erosion (see discussion in text).

\subsection{Estimating Shortening Rate From Fold Width}

[35] One quantitative consequence of this qualitative scenario is that topographic relief width is a simple function of the spatial distribution of uplift and the sedimentation rates. Shortly after the initiation of relief, the fold width should equate to the width of the area where the uplift rate is greater than the sedimentation rate. Using our parameterized deformation models for the Yakeng and Anjihai folds, we plot in Figure 22 the predicted emergence width as a function of the ratio between the shortening and sedimentation rates. The ratios consistent with the observed fold widths are 5.0 for Yakeng, and 4.15 for Anjihai. Assuming that across-fold variations of uplift are large compared to that of the modern (postemergence) sedimentation rates, and combining the predicted ratios with relevant magnetostratigraphic sedimentation rates yields first-order estimates of the mean shortening rates since relief emergence, $2.15 \mathrm{~mm} / \mathrm{yr}$ at Yakeng and $1.12 \mathrm{~mm} / \mathrm{yr}$ at Anjihai, both much faster than the long-term averages (estimated to $\sim 0.17$ and $<0.4 \mathrm{~mm} / \mathrm{yr}$, respectively). Furthermore, at Yakeng, if the cumulative shortening experienced by $\mathrm{Ta}$ is indeed of the order of $320 \mathrm{~m}$ (Figure 11b), its age can be estimated from the $2.15 \mathrm{~mm} / \mathrm{yr}$ shortening rate, which would yield $\sim 150 \mathrm{kyr}$, and the thickness of sediments above the retro-deformed trend of Ta (on the order of 125 and $65 \mathrm{~m}$, upstream and downstream from the fold, respectively, see Figure 11b) would be consistent with 0.83 and $0.43 \mathrm{~mm} / \mathrm{yr}$ of sedimentation, respectively, consistent with the expected ponding of sediments above the NW limb of the emerging ridge. While the precision and reliability of this fold width method will depend on our ability to understand the complexities of the postemergence sedimentation regime, surface fold width stands out as a remarkably sensitive measurement, governed as it is by competition between two important geomorphic processes.

[36] In order to attribute relief emergence at Yakeng and Anjihai to reduced sedimentation rates alone, one would need to accumulate cumulative shortening on the order of several hundreds of meters during this slow sedimentation stage ( $\sim 320 \mathrm{~m}$ at Yakeng and a significant portion of the finite shortening across Anjihai), over durations on the order of millions of years. It is difficult to reconcile such a scenario with the available magnetostratigraphic data and the observed sedimentation on the outer limbs of both folds. On the other hand, because of the competition between tectonic uplift and sedimentation, underestimating the Quaternary sedimentation rates would result in underestimating recent shortening rates, which would argue for an even stronger recent acceleration of shortening across the folds.

\subsection{Evidence for Distributed Strain and Strain Weakening During Fault Tip Folding}

[37] In both cases analyzed here, as well as in the study of the Pakuashan anticline [Simoes et al., 2007b], the stratigraphic and geomorphic record of fold growth are

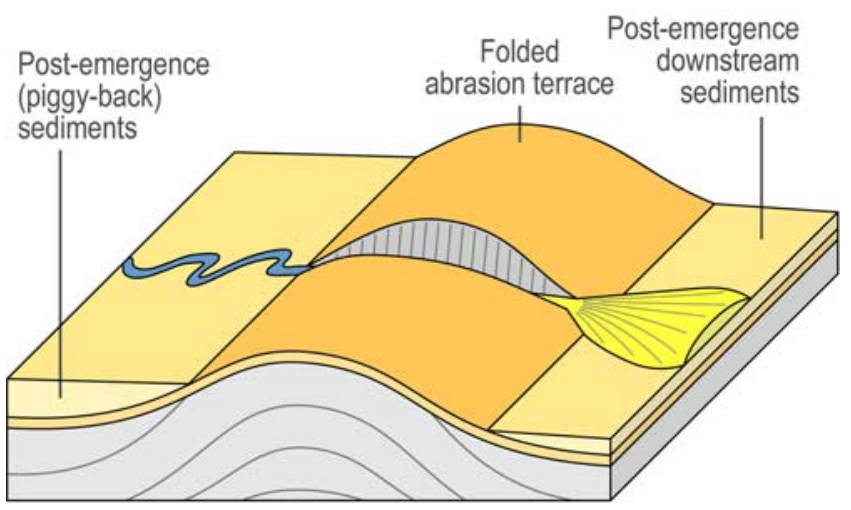

Figure 21. Surface expression of fold after relief emergence, corresponding to Figure 20c. Sedimentation is perturbed by rapid accumulation of sediments upstream of fold, in piggyback basin, and by secondary alluvial fans downstream of it. 


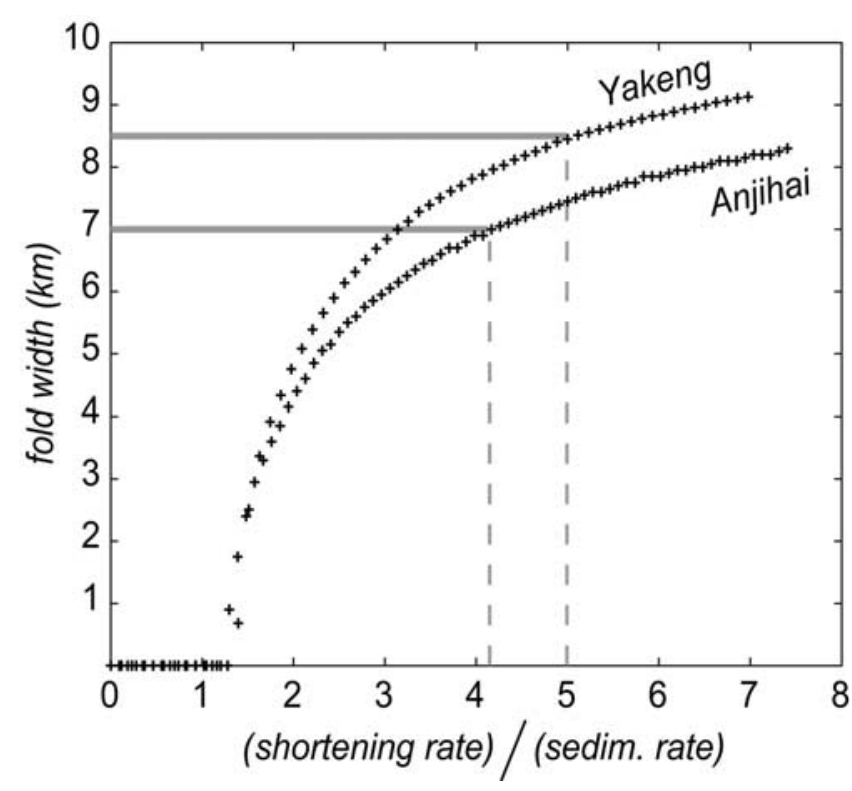

Figure 22. Predicted fold width at the initiation of relief emergence, as a function of the ratio of shortening and sedimentation rates. The observed fold widths correspond to ratios of 5.0 (Yakeng) and 4.15 (Anjihai). Combined with the relevant magnetostratigraphic sedimentation rates, these ratios imply modern shortening rates of 2.15 and $1.12 \mathrm{~mm} / \mathrm{yr}$, respectively.

reasonably well modeled using an analytical formulation which assumes linearly distributed shortening across the fold zone. In addition, in all three cases, cumulative strain is about $10-12 \%$, suggesting that the model applies at least up to that level strain. Furthermore, the two cases discussed here offer compelling evidence that the shortening rates must have increased during folding. We suspect that this behavior reflects strain weakening during in the early stage of folding, when the underlying detachment is still blind. The slow, early stage of folding might correspond to a period of maturation during which rocks are progressively softened by damage, before strain migrates basinward. This phase must result from a gradual transfer of strain to the frontal folds, from more mature fold-and-thrust structures (Quilitag and Huo'erguosi anticlines, respectively). Better understanding of such behavior will likely require comparing the shortening histories of adjacent fold-and-thrust systems, using similar methods as that discussed here [see also Hubert-Ferrari et al., 2007].

\section{Conclusion}

[38] The two case examples detailed in this study illustrate the merits of jointly analyzing the stratigraphic and geomorphic record of folding using a quantitative geometric description of folding. This approach makes it possible to estimate cumulative shortening recorded by markers that are only locally observed, whereas the area conservation method only applies to isochronous markers which can be traced continuously across the fold. Moreover, the method itself does not rely on a specific analytical description of displacements, and could thus be used to test various descriptions of fold deformation. Most importantly, our approach provides a framework in which to combine shortening data from various sources, surface morphology, structural outcrops, seismic profiles, which document folding
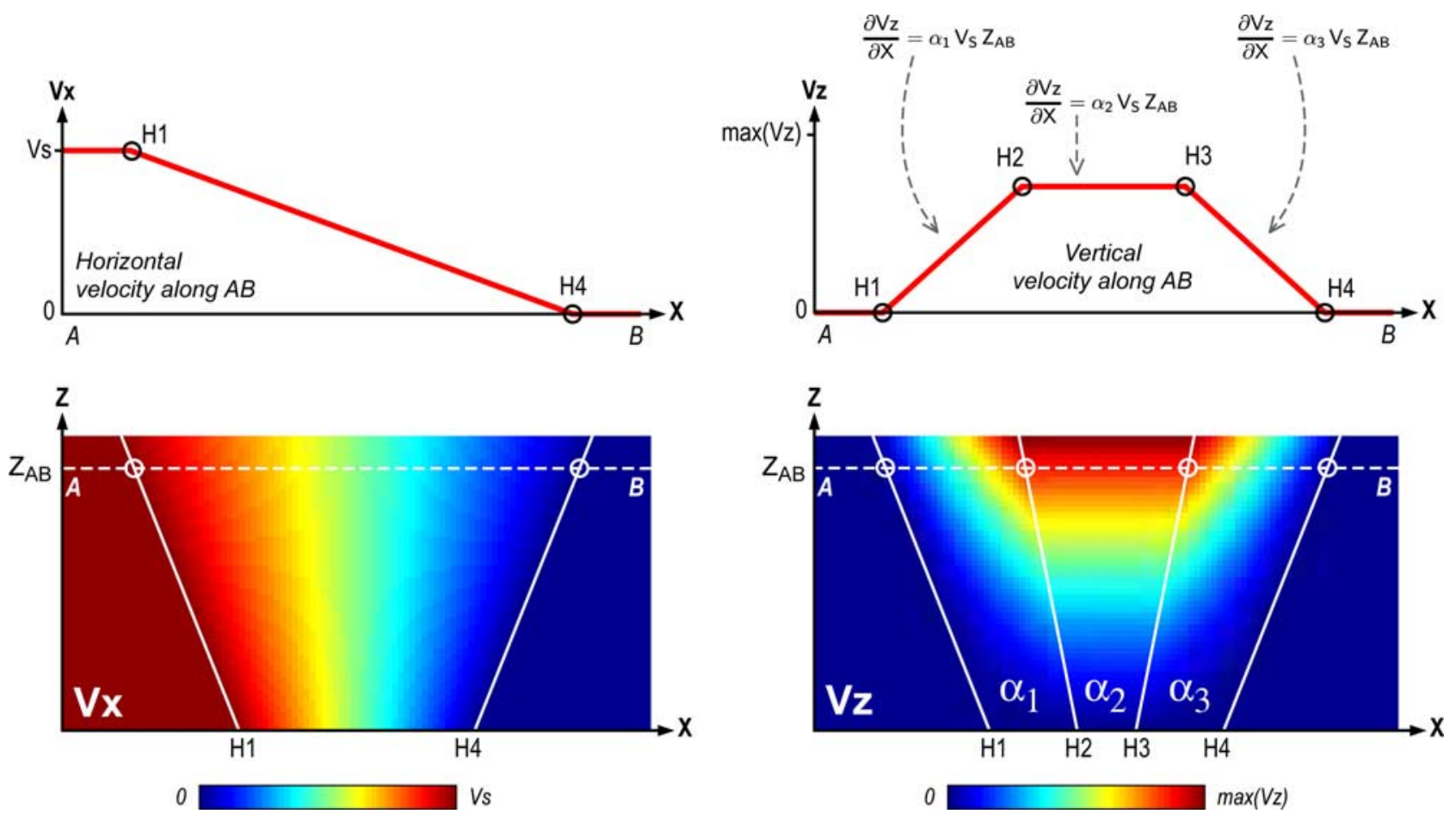

Figure A1. Simplified plot of $\mathrm{Vx}$ and $\mathrm{Vz}$ dependence on $(\mathrm{X}, \mathrm{Z})$ used in our folding models, modified from Bernard et al. [2007]. 
over very different timescales, thus offering an opportunity to study long-term variations of tectonic rates.

\section{Appendix A: A Kinematic Model}

[39] Analog modeling by Bernard et al. [2007], using sandbox experiments, supports a simple first-order description of the cross-sectional velocity field above a detachment fault tip fold. Their formulation describes horizontal and vertical components of motion as varying linearly in space within a series of $(\mathrm{X}, \mathrm{Z})$ domains bounded by hinge lines. In the early stage of fold development (i.e., before the system evolves toward more localized strain), the observed locations of the hinge lines vary little, while material passes through them from one hinge-bounded domain to the next, consistent with a stationary approximation of the velocity field.

[40] Using this purely kinematic description of deformation, one can incrementally model the progressive folding arbitrary geometric objects. While the analytical expression of velocities constitutes a simplification of the natural fold system, it is generally possible to fit the finite geometries of real-world folds, using only a limited number of model parameters. For instance, Simoes et al. [2007b] used this approach to reconcile the finite and incremental deformation recorded by the Pakuashan anticline, in western Taiwan, and to estimate the finite amount and modern rate of shortening across the fold.

[41] The model's reference frame is a 2-D cross section of the fold, similar to that shown in Figure 1, where the lower block is fixed. In the case of the thrust ramp systems considered in this study, this fixed block corresponds to the footwall, basinward from the fold. In this plane, $X$ is horizontal, increasing basinward, and $\mathrm{Z}$ is vertical, increasing upward. In response to an arbitrary rate Vs of acrossfold shortening, the $\mathrm{X}$ and $\mathrm{Z}$ components of velocity are noted Vx and Vz. Velocities far "ahead" (basinward) of the fold or below the detachment level $(\mathrm{Z}<\mathrm{Zd})$ are nil. Velocities far "behind" the fold and above $Z d$ are uniform and horizontal, equal to the slip rate on the detachment. Between these two blocks, in the folding area, $\mathrm{Vx}$ and $\mathrm{Vz}$ are continuous functions of $(\mathrm{X}, \mathrm{Z})$ which vary with $\mathrm{X}$ and $\mathrm{Z}$ in a series of spatial domains bounded by hinge lines ( $\mathrm{H} 1$, $\mathrm{H} 2$, etc.).

[42] Along any arbitrary horizontal line $\left(\mathrm{AA}^{\prime}\right), \mathrm{Vx}$ varies linearly from Vs (the total rate of shortening across the fold) on the first hinge line, $\mathrm{H} 1$, to zero on the last hinge line $\mathrm{Hn}$ (Figure A1). In the model, Vx is thus entirely defined by the shortening rate Vs and the positions of the first and last hinges. Along the same line ( $\left.\mathrm{AA}^{\prime}\right), \mathrm{Vz}$ varies linearly with $\mathrm{X}$ in each hinge-bounded domain (Figure A1), and $\partial \mathrm{Vz} / \partial \mathrm{X}$ is proportional to the height above detachment:

$$
\partial \mathrm{Vz} / \partial \mathrm{X}=\alpha \mathrm{Vs}(\mathrm{Z}-\mathrm{Zd})
$$

The parameter $\alpha$ differs from one hinge-bounded domain to another, but is constant within in each domain. As a result of the dip of hinge lines, $\mathrm{Vz}(\mathrm{Z})$ has a small quadratic component, but in the particular case where all hinge lines are vertical, $\mathrm{Vz}$ varies linearly with $\mathrm{Z}$.

[43] Acknowledgments. We are most grateful to John Suppe, Aurélia Hubert-Ferrari, and Ramon Gonzalez-Mieres for sharing their results with us ahead of publication. We are also indebted to John Suppe, Martine Simoes, and Stéphane Dominguez for fruitful discussion. M. Daëron is grateful for the support of the École Doctorale de l'École Polytechnique, which supported this work through a "Jeune Post-Doc" grant in 2005. This study was partly funded by the Gordon and Betty More Foundation. This is Caltech Tectonics Observatory contribution 48 .

\section{References}

Almendinger, R. (1998), Inverse and forward numerical modeling of trishear fault propagation folds, Tectonics, 17, 640-656.

Avouac, J.-P., P. Tapponnier, M. Bai, H. You, and G. Wang (1993), Active thrusting and folding along the northern Tien-Shan and Late Cenozoic rotation of the Tarim relative to Dzungaria and Kazakhstan, J. Geophys. Res., 98(B4), 6755-6804.

Benedetti, L., P. Tapponnier, G. King, B. Meyer, and I. Manighetti (2000), Growth folding and active thrusting in the Montello region, Veneto, northern Italy, J. Geophys. Res., 105(B1), 739-766.

Bernard, S., J. P. Avouac, S. Dominguez, and M. Simoes (2007), Kinematics of fault-related folding derived from a sandbox experiment, J. Geophys. Res., 112, B03S12, doi:10.1029/2005JB004149.

Bullen, M., D. Burbank, J. Garver, and K. Abdrakhmatov (2001), Late Cenozoic tectonic evolution of the northwestern Tien Shan: New age estimates for the initiation of mountain building, Geol. Soc. Am. Bull, 113(12), 1544-1559.

Burchfiel, B., E. Brown, Q. Deng, X. Feng, J. Li, P. Molnar, J. Shi, Z. Wu, and H. You (1999), Crustal shortening on the margins of the Tien Shan, Xinjiang, China, Int. Geol. Rev., 41(8), 665-700.

Burtman, V. (1975), Structural geology of Variscan Tien Shan, USSR, Am. J. Sci., A275, 157-186.

Charreau, J. (2005), Evolution tectonique du Tianshan au Cénozoïque liée à la collision Inde-Asie: Apport de la magnétostratigraphie et de la géochronologie isotopique U-Th/He, Ph.D. thesis, Univ. d'Orléans, Orléans, France.

Charreau, J., Y. Chen, S. Gilder, S. Dominguez, J.-P. Avouac, S. Sen, D. Sun, Y. Li, and W. Wang (2005), Magnetostratigraphy and rock magnetism of the Neogene Kuitun He section (northwest China): Implications for Late Cenozoic uplift of the Tianshan mountains, Earth Planet. Sci. Lett., 230, 177-192.

Charreau, J., S. Gilder, Y. Chen, S. Dominguez, J.-P. Avouac, S. Sen, M. Jolivet, Y. Li, and W. Wang (2006), Magnetostratigraphy of the Yaha section, Tarim Basin (China): $11 \mathrm{Ma}$ acceleration in erosion and uplift of the Tian Shan mountains, Geology, 34(3), 181-184, doi:10.1130/G22106.1.

Dahlstrom, C. D. A. (1990), Geometric constraints derived from the law of conservation of volume and applied to evolutionary models for detachment folding, AAPG Bull., 74(3), 336-344.

Dumitru, T., D. Zhou, E. Chang, S. Graham, M. Hendrix, E. Sobel, and A. Carroll (2001), Uplift, exhumation, and deformation in the Chinese Tian Shan, Mem. Geol. Soc. Am., 194.

Epard, J., and R. Groshong (1993), Excess area and depth to detachment, Am. Assoc. Pet. Geol. Bull., 77(8), 1291-1302.

Gonzalez-Mieres, R., and J. Suppe (2006), Relief and shortening in detachment folds, J. Struct. Geol., 28(10), 1785-1807.

Hardy, S., and J. Poblet (1994), Geometric and numerical model of progressive limb rotation in detachment folds, Geology, 22, 371-374.

He, D., J. Suppe, G. Yang, S. Guan, S. Huang, X. Shi, X. Wang, and C. Zhang (2005), Guidebook for field trip in South and North Tianshan foreland basin, ZinJiang Yugur Autonomous Region, China, Res. Inst. of Pet. Explor. and Dev., PetroChina, Beijing.

Hendrix, M., T. Dumitru, and A. Graham (1994), Late Oligocene-early Miocene unroofing in the Chinese Tian Shan: An early effect of the IndiaAsia collision, Geology, 22, 487-490.

Hubert-Ferrari, A., J. Suppe, X. Wang, and C. Jia (2005), The Yakeng detachment fold, South Tianshan, China, in Seismic Interpretation of Contractional Fault-Related Folds, edited by J. Shaw, J. Connors, and J. Suppe, pp. 110-113, Am. Assoc. of Pet. Geol., Tulsa, Okla.

Hubert-Ferrari, A., J. Suppe, R. Gonzalez-Mieres, and X. Wang (2007), Mechanisms of active folding of the landscape (southern Tian Shan, China), J. Geophys. Res., doi:10.1029/2006JB004362, in press.

Lavé, J., and J.-P. Avouac (2000), Active folding of fluvial terraces across the Siwaliks Hills, Himalayas of central Nepal, J. Geophys. Res., 105(B3), 5735-5770.

Métivier, F., and Y. Gaudemer (1997), Mass transfer between eastern Tien Shan and adjacent basins (central Asia): Constraints on regional tectonics and topography, Geophys. J. Int., 128, 1-17.

Métivier, F., Y. Gaudemer, P. Tapponnier, and M. Klein (1999), Mass accumulation rates in Asia during the Cenozoic, Geophys. J. Int., 137, $280-318$.

Mitra, S. (2003), A unified kinematic model for the evolution of detachment folds, J. Struct. Geol., 25(10), 1659-1673. 
Molnar, P., et al. (1994), Quaternary climate-change and the formation of river terraces across growing anticlines on the north flank of the TienShan, China, J. Geol., 102, 583-602.

Poisson, B. (2002), Impact du climat et de la tectonique sur l'évolution géomorphologique d'un piémont. exemple du piémont Nord du Tien Shan depuis la fin du Pléistocène, Ph.D. thesis, Univ. de Paris XI, Orsay, France.

Poisson, B., and J. P. Avouac (2004), Holocene hydrological changes inferred from alluvial stream entrenchment in north Tian Shan (northwestern China), J. Geol., 112, 231-249.

Reigber, C., et al. (2001), New space geodetic constraints on the distribution of deformation in central asia, Earth Planet. Sci. Lett., 191(1-2), $157-165$.

Rockwell, T., E. Keller, and G. Dembroff (1988), Quaternary rate of folding of the Ventura Avenue anticline, western Transverse Ranges, southern California, Geol. Soc. Am. Bull., 100(6), 850-858, doi:10.1130/00167606(1988)100<0850:QROFOT >2.3.CO;2.

Simoes, M., J.-P. Avouac, Y.-G. Chen, A. K. Singhvi, C.-Y. Wang, M. Jaiswal, Y.-C. Chan, and S. Bernard (2007b), Kinematic analysis of the Pakuashan fault tip fold, west central Taiwan: Shortening rate and age of folding inception, J. Geophys. Res., 112, B03S14, doi:10.1029/ 2005JB004198

Sobel, E. R., and T. A. Dumitru (1997), Thrusting and exhumation around the margins of the western Tarim basin during the India-Asia collision, J. Geophys. Res., 102(B3), 5043-5063.

Storti, F., and J. Poblet (1997), Growth stratal architectures associated to decollement folds and fault-propagation folds: Inferences on fold kinematics, Tectonophysics, 282(1-4), 353-373.
Suppe, J. (1983), Geometry and kinematics of fault-bend folding, Am. J. Sci., 283, 684-721.

Suppe, J., and D. A. Medwedeff (1990), Geometry and kinematics of faultpropagation folding, Eclogae Geol. Helv., 83(3), 409-454.

Suppe, J., G. T. Chou, and S. C. Hook (1992), Rates of folding and faulting determined from growth strata, in Thrust Tectonics, edited by K. R. McClay, pp. 105-121, CRC Press, Boca Raton, Fla.

Tapponnier, P., and P. Molnar (1977), Active faulting and tectonics in China, J. Geophys. Res., 82(20), 2905-2930.

Thompson, S., R. Weldon, C. Rubin, K. Abdrakhmatov, P. Molnar, and G. Berger (2002), Late Quaternary slip rates across the central Tien Shan, Kyrgyzstan, central Asia, J. Geophys. Res., 107(B9), 2203, doi:10.1029/2001JB000596.

Windley, B., M. Allen, C. Zhang, Z. Zhao, and G. Wang (1990), Paleozoic accretion and Cenozoic redeformation of the Chinese Tien Shan Range, central Asia, Geology, 18(2), 128-131.

Zhang, P., P. Molnar, and W. Downs (2001), Increased sedimentation rates and grain sizes 2-4 Myr ago due to the influence of climate change on erosion rates, Nature, 410, 891-897.

J.-P. Avouac and M. Daëron, Division of Geological and Planetary Sciences, California Institute of Technology, MC 100-23, Pasadena, CA 91125, USA. (avouac@gps.caltech.edu; daeron@gps.caltech.edu)

J. Charreau, Institut des Sciences de la Terre d'Orléans, Rue St Amand, F-45067 Orleans, France. (julien.charreau@univ-orleans.fr) 